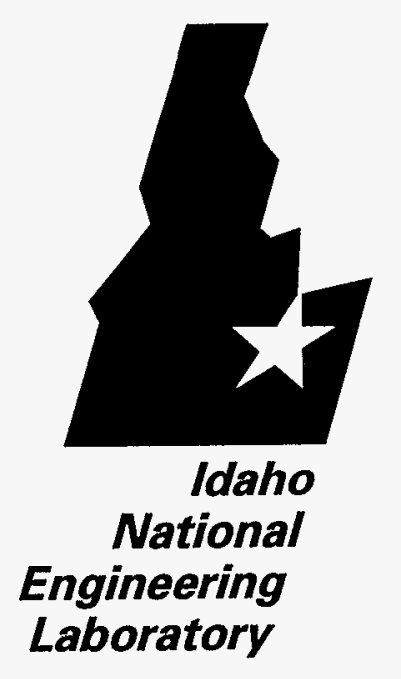

$$
\begin{gathered}
\text { INEL- } 94 / 0231 \\
\text { OCT } 271995 \\
\text { OSTI }
\end{gathered}
$$

Cooperative Telerobotic Retrieval System Phase 1 Technology Evaluation Report

R. A. Hyde

K. M. Croft 


\section{DISCLAIMER}

This report was prepared as an account of work sponsored by an agency of the United States Government. Neither the United States Government nor any agency thereof, nor any of their employees, makes any warranty, express or implied, or assumes any legal liability or responsibility for the accuracy, completeness, or usefulness of any information, apparatus, product or process disclosed, or represents that its use would not infringe privately owned rights. References herein to any specific commercial product, process, or service by trade name, trademark, manufacturer, or otherwise, does not necessarily constitute or imply its endorsement, recommendation, or favoring by the United States Government or any agency thereot. The views and opinions of authors expressed herein do not necessarily state or reflect those of the United States Government or any agency thereof. 


\section{DISCLAMMER}

Portions of this document may be illegible in electronic image products. Images are produced from the best available original document. 


\title{
Cooperative Telerobotic Retrieval System Phase 1 Technology Evaluation Report
}

\author{
R. A. Hyde \\ K. M. Croft
}

Published March 1995

Idaho National Engineering Laboratory Lockheed Idaho Technologies Company Idaho Falls, Idaho 83415

Prepared for the

U.S. Department of Energy

Assistant Secretary for Environmental Management Under DOE Idaho Operations Office

Contract DE-AC07-941D13223 


\section{Cooperative Telerobotic Retrieval System Phase 1 Technology Evaluation Report}

INEL-94/0231

Prepared by:

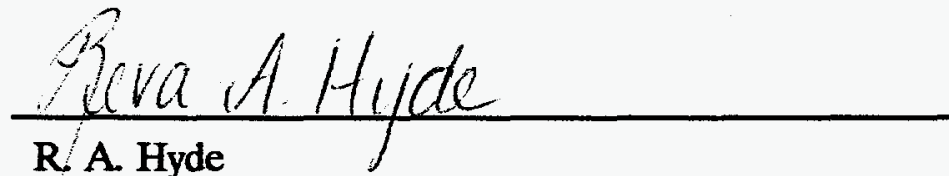

Senior Engineer

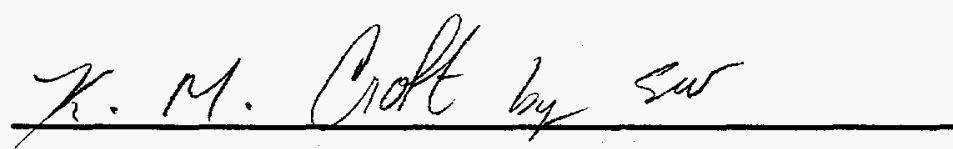

K. M. Croft

Principal Investigator

Reviewed by:

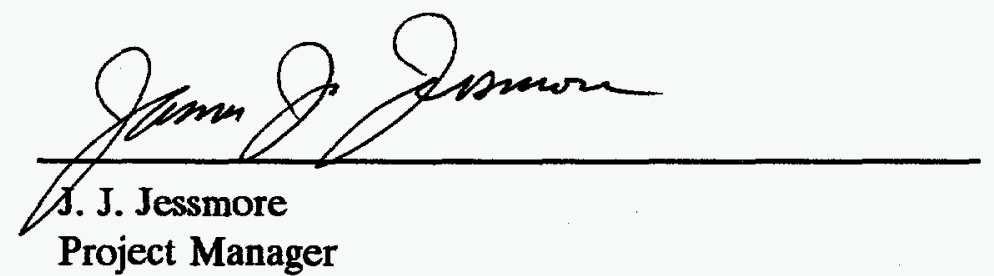

Project Manager

Approved by:

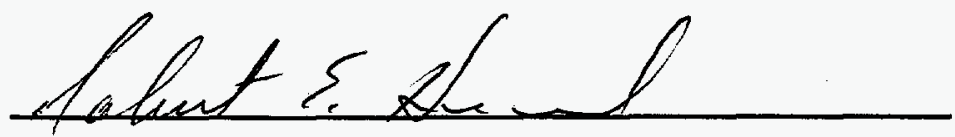

R. E. Heard

Deployment Program Manager
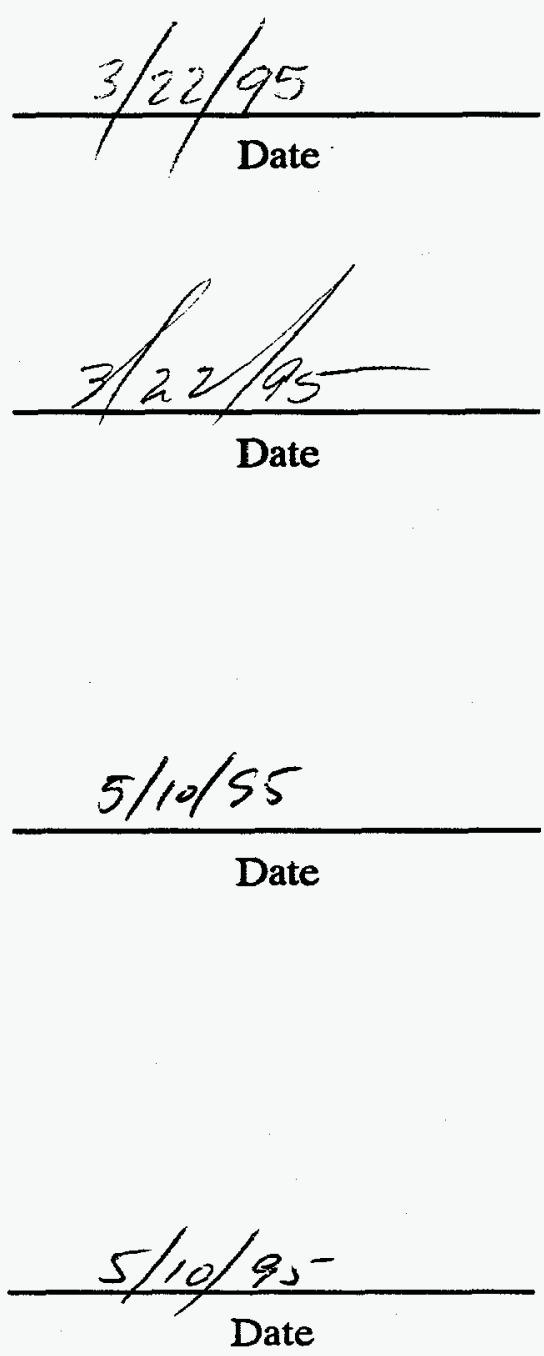


\begin{abstract}
This document describes the results from the Cooperative Telerobotic Retrieval demonstration and testing conducted at the Idaho National Engineering Laboratory during December 1994 and January 1995. The purpose of the demonstration was to ascertain the feasibility of the system for deploying tools both independently and cooperatively for supporting remote characterization and removal of buried waste in a safe manner and in compliance with all regulatory requirements. The procedures and goals of the demonstration were previously defined in the Cooperative Telerobotic Retrieval System Test Plan for Fiscal Year 1994, which served as a guideline for evaluating the system.
\end{abstract}




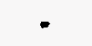




\section{EXECUTIVE SUMMARY}

In December 1994 and January 1995, the Cooperative Telerobotic Retrieval (CTR) system was successfully demonstrated at the Idaho National Engineering Laboratory (INEL). The thrust of the project was to demonstrate the feasibility of implementing a remotely controlled gantry crane for deploying waste characterization, excavation, and retrieval support tools. The tests focused on the capabilities of the crane for independent as well as cooperative movement of two independent robotic manipulators and two vertically telescoping masts.

The results of the tests on the remotely operated gantry crane are presented in this report. The results show the capabilities of the crane as a delivery system, the system's ability to perform two independent tasks, the ability of the two Schilling manipulators to cooperate to accomplish various tasks, and the crane's control system interface. Also presented in this report is information on failures, system deficiencies, maintenance, and effects the environment has on operation. In addition, this report discusses full-scale implementation of the remote system, giving special attention to schedule and cost issues and suggested system enhancements.

The CTR system was tested as a delivery system for accuracy and precision (repeatability) at various speeds for movements along the $\mathrm{x}$ (along the rails), $\mathrm{y} 1$ (trolley A across the girder), $\mathrm{z} 1$ (trolley A vertically), and xy1z1 axes. Speed of movement was shown to have very little effect on the accuracy and precision for each of the axes tested. The movements were extremely repeatable. The accuracy data quality objective was to be within \pm 1 in. All axes met this objective. The accuracies can be even further improved by replacing the encoders with ones that have a higher resolution (i.e., increased number of counts per inch) and by fine tuning the axes.

Independent movement was also successfully demonstrated. One z-mast deployed a simulated sensor and performed a raster scan of a $10 \mathrm{ft}$ by $10 \mathrm{ft}$ area. Simultaneously, the other z-mast deployed a camera that was independently moved to watch the simulated sensor. Planning of a three-point plane took between $2-4.5$ minutes, while execution of that $10 \mathrm{ft}$ by $10 \mathrm{ft}$ plane took approximately 5 minutes.

Vacuum tests were also performed, both robotically (from trolley A) and manually. The tests successfully demonstrated that vacuuming could be accomplished robotically by using a threepoint scan. The tests revealed that manual vacuuming was faster and more effective than robotic deployment and was thought to be due to "finessing" the nozzle. Improvements in robotic deployment of the vacuum could be made by using a more powerful vacuum and/or using a "soil busting" technology.

Cooperative movement objectives were achieved through a series of tests, including rigging and movement of a 55-gal drum, deploying a camera up close for information regarding the other manipulator's activities, and handing an object from one manipulator to the other. These tasks demonstrated cooperative movement of the CTR system.

Several hardware and software failures occurred during testing. While the number of failures was not unreasonable for prototype equipment, the failures did delay completion of the tests. These failures as well as system deficiencies are discussed in this report. 
Environmental effects on the system are also discussed in this report. Temperature had an adverse effect on the CTR system, while wind and precipitation did not affect operations.

Finally, operators' opinions about the console were documented. The console could be improved by allowing adjustability of the screens and table top, reviewing the display screens and control mechanisms from a human factors perspective, and implementing stereovision.

Through these tests, the CTR system was shown not only to be a safer method for waste site characterization and retrieval than conventional manual methods, but it is also a less expensive method, allowing for better control over and repeatability of positioning of sensors and tools, and a faster method for deploying characterization tools. 


\section{ACKNOWLEDGMENTS}

The efforts of all members of the Cooperative Telerobotic Retrieval system team were required to successfully complete the testing and this report. The authors wish to acknowledge Scott Allen, Wayne Boyer, Lorin Hansen, Stephanie Walker, Ken Beard, Lisa Meikle, and Stuart Walsh for their technical contributions to the project and this report. The authors also wish to acknowledge Mark DeHaan for aiding in the statistical analysis of the data, Don Sparhawk for aiding in the technical editing of this report, and Jim Jessmore for project management support. 


\section{CONTENTS}

ABSTRACT $\ldots \ldots \ldots \ldots \ldots \ldots \ldots \ldots \ldots \ldots \ldots \ldots \ldots \ldots \ldots \ldots \ldots \ldots \ldots \ldots \ldots$, iii

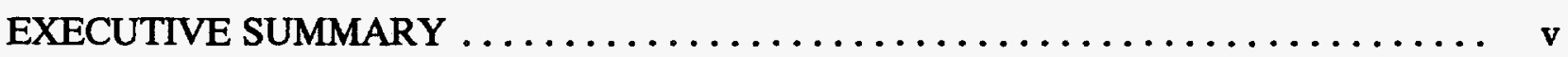

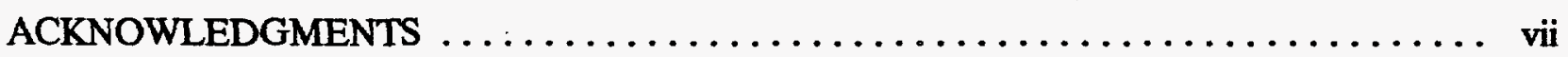

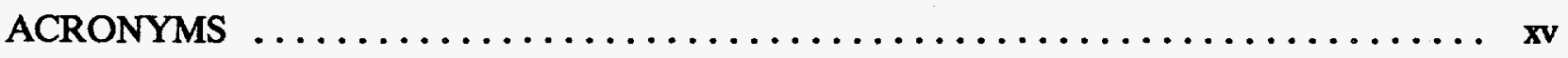

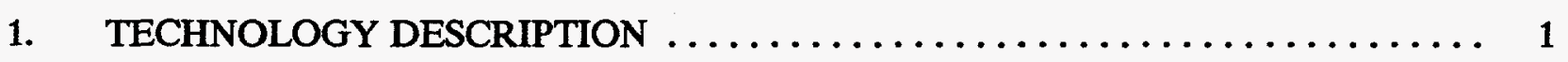

1.1 System Description $\ldots \ldots \ldots \ldots \ldots \ldots \ldots \ldots \ldots \ldots \ldots \ldots \ldots \ldots \ldots \ldots \ldots$

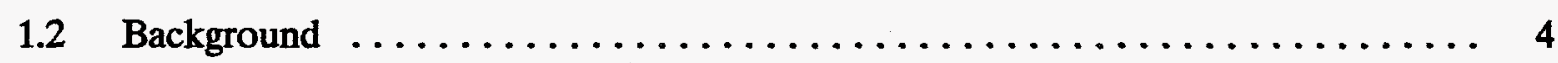

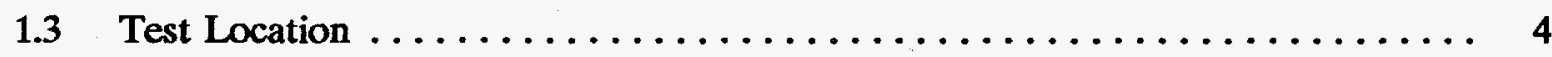

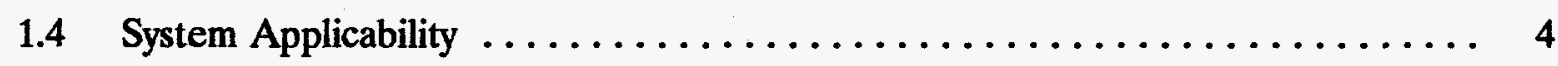

1.5 Technology Need $\ldots \ldots \ldots \ldots \ldots \ldots \ldots \ldots \ldots \ldots \ldots \ldots \ldots$

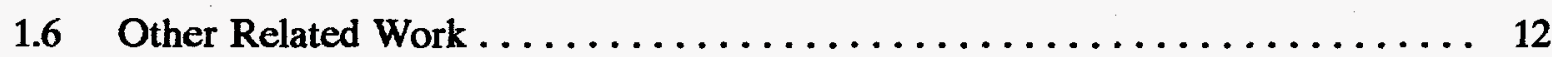

1.7 Technology Commercialization and Implementation $\ldots \ldots \ldots \ldots \ldots \ldots$

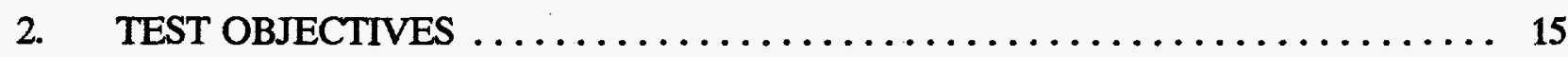

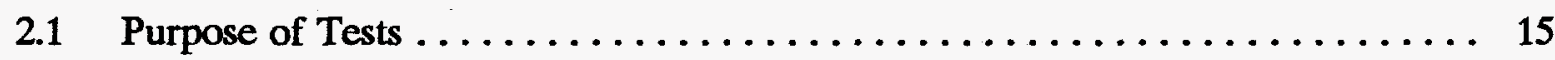

2.2 Test Objectives and Data Quality Objectives ................. 15

3. EXPERIMENTAL DESIGN AND PROCEDURES $\ldots \ldots \ldots \ldots \ldots \ldots \ldots \ldots$

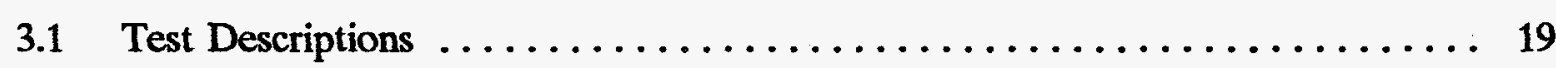

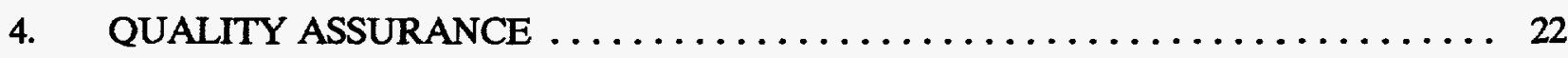

4.1 Internal Quality Control Checks $\ldots \ldots \ldots \ldots \ldots \ldots \ldots \ldots \ldots \ldots \ldots \ldots \ldots \ldots \ldots \ldots$

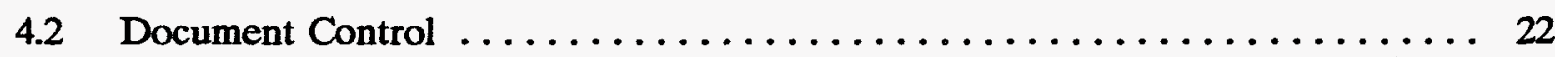

4.3 System Configuration Management $\ldots \ldots \ldots \ldots \ldots \ldots \ldots \ldots \ldots \ldots \ldots \ldots$

5. HEALTH AND SAFETY $\ldots \ldots \ldots \ldots \ldots \ldots \ldots \ldots \ldots \ldots \ldots \ldots \ldots \ldots \ldots \ldots \ldots \ldots \ldots$

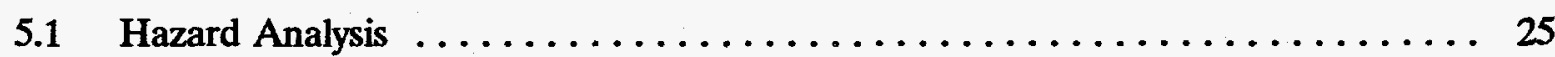




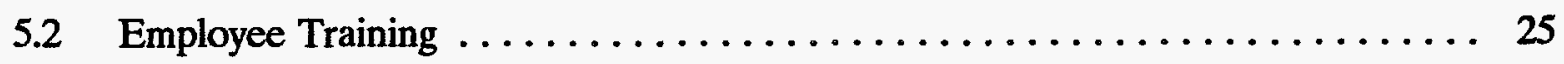

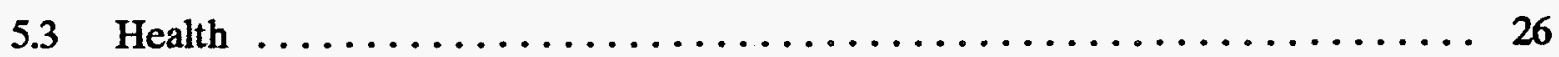

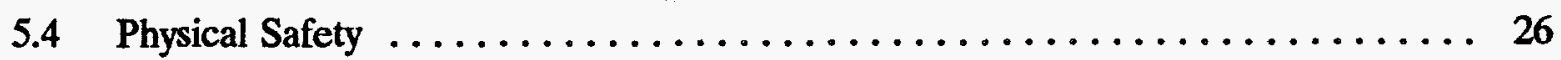

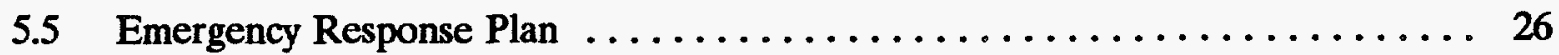

6. ENVIRONMENTAL OVERVIEW $\ldots \ldots \ldots \ldots \ldots \ldots \ldots \ldots \ldots \ldots \ldots \ldots \ldots \ldots$

6.1 National Environmental Policy Act $\ldots \ldots \ldots \ldots \ldots \ldots \ldots \ldots \ldots \ldots \ldots$

6.2 Occupational Safety and Health Administration $\ldots \ldots \ldots \ldots \ldots \ldots \ldots .27$

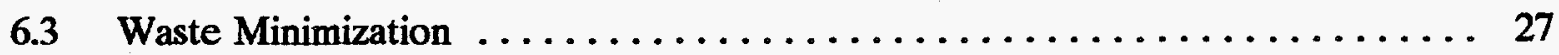

6.4 Environmental Issues During Testing $\ldots \ldots \ldots \ldots \ldots \ldots \ldots \ldots \ldots \ldots, 27$

7. TEST RESULTS $\ldots \ldots \ldots \ldots \ldots \ldots \ldots \ldots \ldots \ldots \ldots \ldots \ldots \ldots \ldots \ldots \ldots \ldots \ldots$

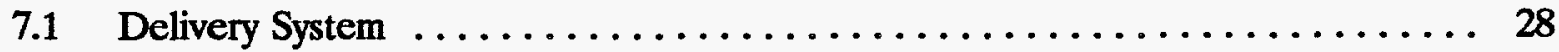

7.2 Independent Movement and Deployment of Tools $\ldots \ldots \ldots \ldots \ldots \ldots . \ldots 31$

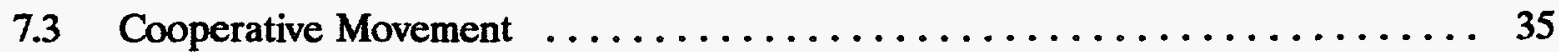

$7.4 \quad$ Failures and System Deficiencies $\ldots \ldots \ldots \ldots \ldots \ldots \ldots \ldots \ldots \ldots \ldots \ldots$

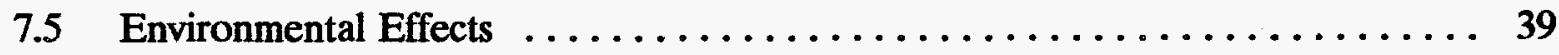

7.6 Human-Computer/Video Interface $\ldots \ldots \ldots \ldots \ldots \ldots \ldots \ldots \ldots \ldots$

7.7 Fulfillment of Data Quality Objectives $\ldots \ldots \ldots \ldots \ldots \ldots \ldots \ldots \ldots \ldots, 40$

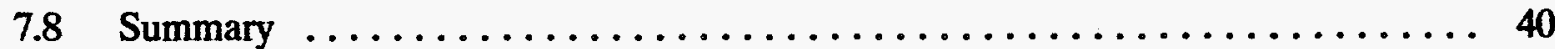

8. OUTPUT/PRODUCTS $\ldots \ldots \ldots \ldots \ldots \ldots \ldots \ldots \ldots \ldots \ldots \ldots \ldots \ldots \ldots \ldots \ldots \ldots \ldots \ldots$

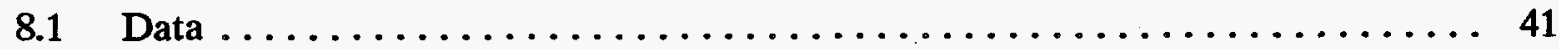

$8.2 \quad$ Video/Photographs $\ldots \ldots \ldots \ldots \ldots \ldots \ldots \ldots \ldots \ldots \ldots \ldots \ldots \ldots, 41$

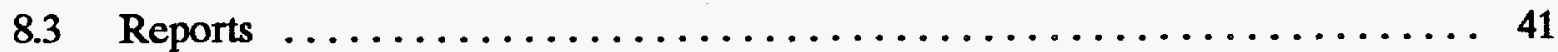

$8.4 \quad$ Residuals $\ldots \ldots \ldots \ldots \ldots \ldots \ldots \ldots \ldots \ldots \ldots \ldots \ldots \ldots \ldots \ldots \ldots \ldots \ldots$

9. PROBLEMS AND ISSUES FROM TESTING $\ldots \ldots \ldots \ldots \ldots \ldots \ldots \ldots \ldots, 42$ 
9.1 Weather $\ldots \ldots \ldots \ldots \ldots \ldots \ldots \ldots \ldots \ldots \ldots \ldots \ldots \ldots \ldots \ldots \ldots \ldots \ldots$

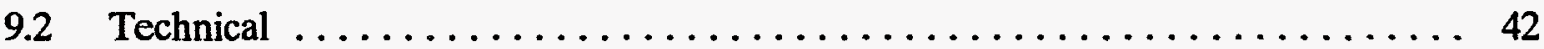

9.3 Schedule $\ldots \ldots \ldots \ldots \ldots \ldots \ldots \ldots \ldots \ldots \ldots \ldots \ldots \ldots \ldots \ldots \ldots$

10. FULL-SCALE IMPLEMENTATION $\ldots \ldots \ldots \ldots \ldots \ldots \ldots \ldots \ldots \ldots \ldots$

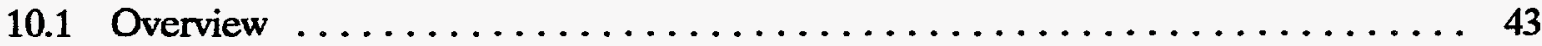

10.2 Implementability $\ldots \ldots \ldots \ldots \ldots \ldots \ldots \ldots \ldots \ldots \ldots \ldots \ldots \ldots \ldots \ldots$

10.3 Effectiveness $\ldots \ldots \ldots \ldots \ldots \ldots \ldots \ldots \ldots \ldots \ldots \ldots \ldots \ldots \ldots \ldots$

10.4 Costs $\ldots \ldots \ldots \ldots \ldots \ldots \ldots \ldots \ldots \ldots \ldots \ldots \ldots \ldots \ldots \ldots \ldots \ldots \ldots$

11. CONCLUSIONS AND RECOMMENDATIONS $\ldots \ldots \ldots \ldots \ldots \ldots \ldots \ldots \ldots$

11.1 Conclusions $\ldots \ldots \ldots \ldots \ldots \ldots \ldots \ldots \ldots \ldots \ldots \ldots \ldots \ldots \ldots \ldots \ldots$

11.2 Recommendations $\ldots \ldots \ldots \ldots \ldots \ldots \ldots \ldots \ldots \ldots \ldots \ldots \ldots \ldots$

12. REFERENCES $\ldots \ldots \ldots \ldots \ldots \ldots \ldots \ldots \ldots \ldots \ldots \ldots \ldots \ldots \ldots \ldots \ldots$

Appendix A-Modified Test Procedures $\ldots \ldots \ldots \ldots \ldots \ldots \ldots \ldots \ldots \ldots \ldots \ldots \ldots \ldots$

Appendix B-Raw Data from the Delivery System Tests . . . . . . . . . . . . . B-1

Appendix $\mathrm{C}-\mathrm{Raw}$ Data from the Vacuum Tests $\ldots \ldots \ldots \ldots \ldots \ldots \ldots \ldots \ldots$

\section{FIGURES}

1. Cooperative Telerobotic Retrieval system $\ldots \ldots \ldots \ldots \ldots \ldots \ldots \ldots \ldots \ldots \ldots$

2. Two robotic manipulators performing independent tasks $\ldots \ldots \ldots \ldots \ldots \ldots$

3. Two robotic manipulators performing a cooperative task $\ldots \ldots \ldots \ldots \ldots \ldots$

\section{TABLES}

1. Potential ER/WM application $\ldots \ldots \ldots \ldots \ldots \ldots \ldots \ldots \ldots \ldots \ldots \ldots$

2. Crane speeds that were tested $\ldots \ldots \ldots \ldots \ldots \ldots \ldots \ldots \ldots \ldots \ldots \ldots$

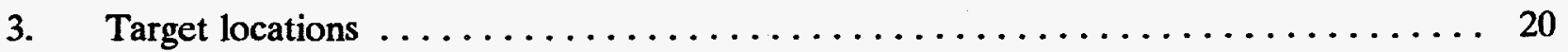


4. Summary of data for moving along $\mathrm{x}$ axis $\ldots \ldots \ldots \ldots \ldots \ldots \ldots \ldots \ldots$

5. Summary of data for moving along yl axis $\ldots \ldots \ldots \ldots \ldots \ldots \ldots \ldots \ldots$

6. Summary of data for moving along $\mathrm{z} 1$ axis $\ldots \ldots \ldots \ldots \ldots \ldots \ldots \ldots$

7. Summary of data for moving along the $x y 1$, and $z 1 \ldots \ldots \ldots \ldots \ldots \ldots$

8. Accuracy and precision values from combined data $\ldots \ldots \ldots \ldots \ldots \ldots \ldots \ldots \ldots$

9. Data from the simulated digface characterization tests $\ldots \ldots \ldots \ldots \ldots \ldots \ldots$

10. Vacuum test data $\ldots \ldots \ldots \ldots \ldots \ldots \ldots \ldots \ldots \ldots \ldots \ldots \ldots \ldots \ldots \ldots$

11. Results from the vacuum tests $\ldots \ldots \ldots \ldots \ldots \ldots \ldots \ldots \ldots \ldots \ldots \ldots \ldots$

12. Partial list of direct capital equipment costs $\ldots \ldots \ldots \ldots \ldots \ldots \ldots \ldots \ldots \ldots$ 


\section{ACRONYMS}

ACECO American Crane and Equipment Corporation

BNL Brookhaven National Laboratory

COBRA Computerized Radioactive Waste Burial Records Analysis Act

CPP Idaho Chemical Processing Plant

CTR Cooperative Telerobotic Retrieval

DOD U.S. Department of Defense

DOE U.S. Department of Energy

DOE-ID U.S. Department of Energy Idaho Operations Office

EDM Electronic Distance Meter

ER Environmental Restoration

FY Fiscal Year

GTCC Greater-Than Class C

INEL Idaho National Engineering Laboratory

ITM Integrated Transfer Module

LLW Low-Level Radioactive Waste

NEPA National Environmental Policy Act

NBA North Boulevard Annex (Robotics Center)

NIST National Institute for Standards and Technology

NOAA National Oceanic and Atmospheric Administration

ORNL Oak Ridge National Laboratory

ORWBG Old Radioactive Waste Burial Ground

OSHA Occupational Safety and Health Administration

OTD Office of Technology Development 


\begin{tabular}{ll} 
OU & Operable Unit \\
PCB & Polychlorinated Biphenyl \\
PI & Principal Investigator \\
RCRA & Resource Conservation and Recovery Act \\
RF & Rocky Flats \\
RFI/RI & RCRA Facility Investigation/Remedial Investigation \\
RI/FS & Remedial Investigation/Feasibility Study \\
RMO & Routine Maintenance Operation \\
RWMC & Radioactive Waste Management Complex \\
SNL & Sandia National Laboratories \\
SR & Savannah River \\
SWSA & Solid Waste Storage Area \\
TRU & Transuranic \\
VOC & Volatile Organic Compound \\
WAG & Waste Area Group \\
WM & Waste Management \\
\hline
\end{tabular}




\section{Cooperative Telerobotic Retrieval System Phase 1 Technology Evaluation Report}

\section{TECHNOLOGY DESCRIPTION}

\subsection{System Description}

As of 1990, the amount of buried waste at U.S. Department of Energy (DOE) sites was estimated at approximately 3.1 million $\mathrm{m}^{3}$. Nearly $50 \%$ of this waste was disposed of prior to 1970 under disposal regulations in effect at that time. These disposal regulations did not require that different types of waste be treated separately; therefore, it is now believed that much of the buried waste is presently contaminated with both hazardous and radioactive materials. Due to incomplete records and the loss of waste container integrity, these wastes present significant remediation challenges.

In support of remediating these wastes, the Idaho National Engineering Laboratory (INEL) is supporting the development of a Cooperative Telerobotic Retrieval (CTR) system as well as other retrieval, characterization, assay, and treatment technologies. These technologies will be tested in a full-scale integrated field test during the summer of FY-95 to evaluate their performance individually and as a complete system in retrieving waste.

The CTR system will provide universal access to the waste area by providing movement in the $x, y$, and $z$ directions. The system consists of an $80-\mathrm{ft}$ wide gantry crane; two trolley assemblies with vertically telescoping masts ( $\mathrm{z}$-masts) each having 22 -ft of vertical travel; six degree-of-freedom manipulators mounted to the base of each z-mast; and a trolley and 5-ton hoist assembly mounted on a separate track. The manipulators mounted on the z-masts provide for dexterous teleoperation, telerobotic operations, or full robotic operations of equipment. Because the manipulators are mounted to the base of the z-masts, they can be used in cooperation with each other or can be operated separately. The manipulators are mounted so that they can be used in cooperation with the hoist hook for remotely attaching or removing a load from the hook The system currently has two closed circuit television cameras mounted to the legs of the crane for visualization of the workspace during operations. The entire crane system consists of 29 degrees of freedom and has closed-loop control using an enhanced commercial robotics control system.

During the FY-95 summer integrated field test at the INEL, the CTR system will be used to support simulated waste retrieval. Hot spot retrieval will be performed using, as one component of the integrated system, the CTR gantry crane equipped with two manipulators that can work together. Figures 1 and 2 show the crane system. The figures depict the $x, y$, and $z$ axes that are referenced throughout this document.

The CTR system will first deploy characterization tools to locate/verify the zone of environmental concern. The system will then operate a vacuum system and various retrieval end effectors to retrieve the simulated source and associated contaminated material. Next, the manipulators will place rigging around the object and connect it to the crane hoist for removal. 
$X$ (In and out of page)

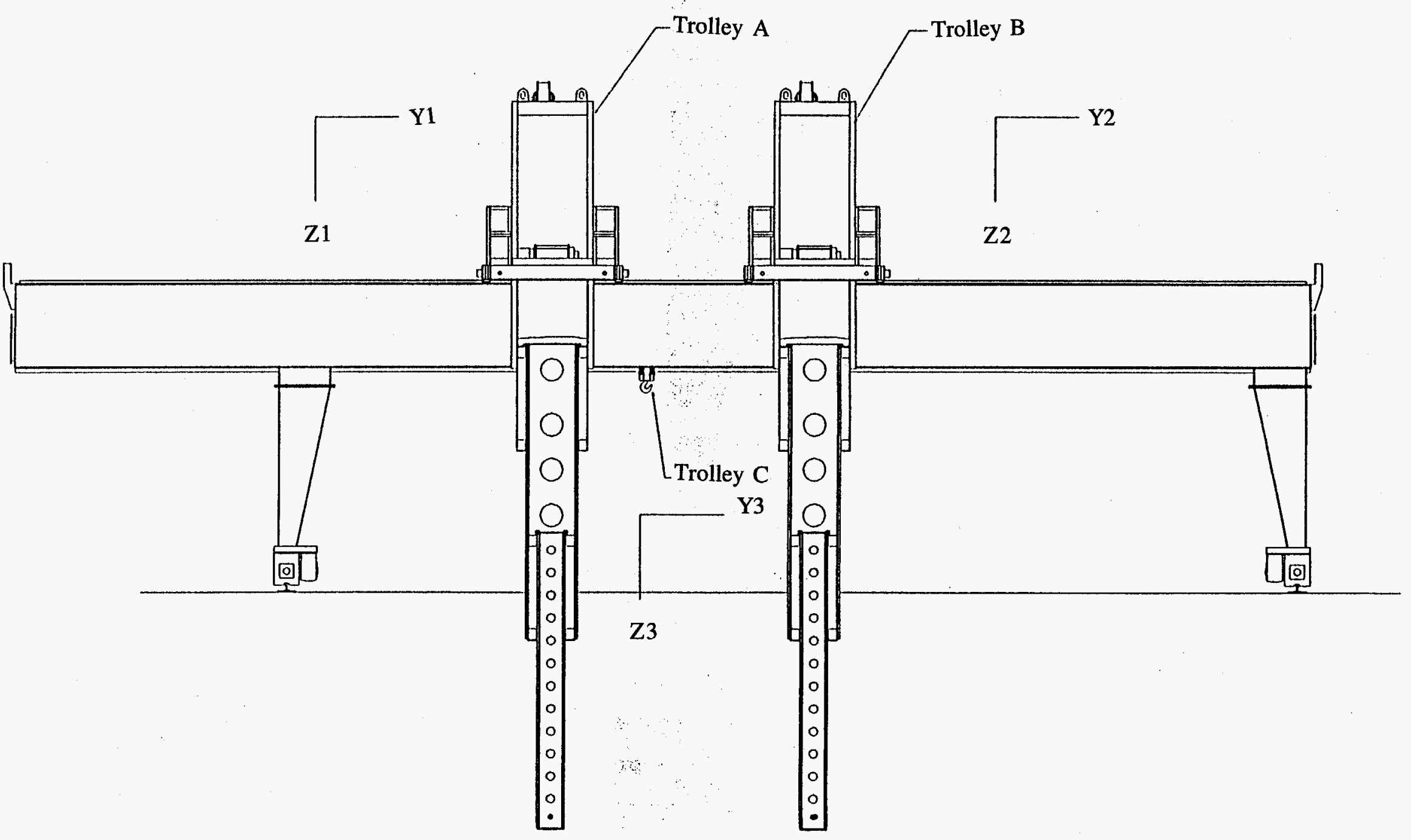

Figure 1. Cooperative Telerobotic Retrieval system. 


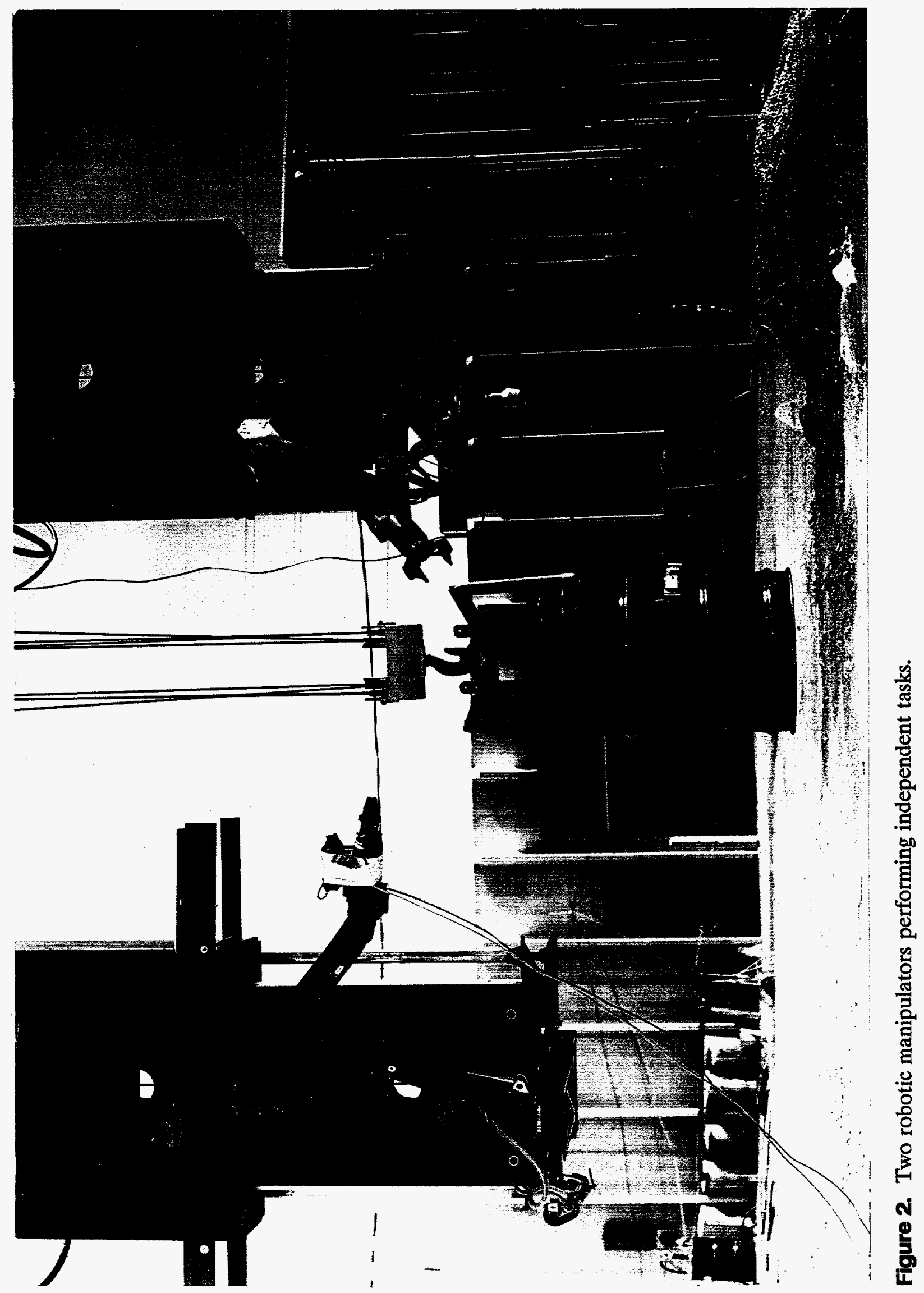


The retrieved waste will be placed in a conveyance waste container for transport out of the retrieval area.

This technology evaluation report describes the tests for the CTR system and evaluates the system for its current development state. Improvements will be made to the system based on the results of the tests described herein to support the FY-95 summer full-scale integrated field test.

\subsection{Background}

Prior to 1970, DOE's primary method for disposal of transuranic (TRU) mixed waste was burial in pits and trenches. As an example, between 1952 and 1970, over 2 million $\mathrm{ft}^{3}$ of waste was buried at the INEL's Radioactive Waste Management Complex (RWMC). The contaminants at the RWMC include plutonium and americium oxides, chlorides, hydroxides, volatile organics (e.g., trichloroethylene and carbon tetrachloride), and cutting oils. The waste containers are assumed to be severely deteriorated, and the waste is expected to be commingled with approximately 10 million $\mathrm{ft}^{3}$ of fill dirt.

DOE is committed to remediating buried waste sites, such as the RWMC, throughout the DOE complex. To meet this commitment, DOE has formed the Office of Technology Development (OTD) to develop, test, demonstrate, and evaluate advanced remediation technologies to be infused into the environmental restoration (ER) and waste management (WM) missions. OTD has, in turn, initiated the buried waste program to support the applied research, development, demonstration, and evaluation of a multitude of advanced technologies. These technologies are being integrated to form a comprehensive remediation system for the effective and efficient remediation of buried waste. To date, the majority of the development effort has focused on a retrieve and treat scenario for the remediation of buried waste. The retrieve and treat scenario involves characterization of the buried waste site, excavation of the waste, ex situ treatment of the exhumed waste, and assaying of the final product. The CTR project supports both characterization and retrieval of wastes.

\subsection{Test Location}

Installation and testing was performed in a designated area behind the North Boulevard Annex (NBA) in Idaho Falls. The only utility required by the CTR system was electric power. Power is presently supplied to the system in various ways. The 40-hp vacuum motor is powered from a $50-\mathrm{kW}$ generator at $480 \mathrm{~V}$. The crane servo amplifiers are powered by a $1.2-\mathrm{kW}$ power supply module. This power supply module can accept a power input range from 65 to $240 \mathrm{Vdc}$ and is powered at $208 \mathrm{Vac}$. There is 110 -Vac service used on the crane for miscellaneous instrumentation. The 7.5-hp motor for the hydraulic pump is run from a 208-Vac power source. All 208-V and 480-V electrical sources provide three-phase power.

\subsection{System Applicability}

The purpose of the CTR system demonstration is to determine the feasibility of remotely controlled retrieval and characterization to demonstrate and evaluate the technology and to determine necessary improvements for the FY-95 summer integrated field test at the INEL. The 
CTR system is amenable to both simulated waste retrieval and support of full-scale retrieval. The applicability of the system to buried waste retrieval is apparent when considering the universal accessibility of the equipment to the area. The system spans the waste site and has the ability to travel the length of the site, without traveling on the buried waste.

The system consists of a gantry crane that has a span between rails of $60 \mathrm{ft}$ and a runway length of $60 \mathrm{ft}$. The span of the crane girder is $80 \mathrm{ft}$, including a $20-\mathrm{ft}$ cantilevered overhang on one end. The crane consists of a single girder that is rectangular in cross section. Three devices currently run on the girder. They are a 5-ton hoist (running alone on one side of the girder) and two z-masts (running on the opposite side of the girder from the hoist). Mounted at the base of each z-mast is a servo-hydraulic manipulator. The girder is sized such that the two z-masts (and manipulators) and the hoist can be used separately or concurrently. Each z-mast has been designed to vertically lift a 2,000 -lb load. The hoist is designed for a 10,000 -lb vertical lift. In addition, the hoist platform is designed for the placement of a 2,000-lb load above the hoist. Altogether, the girder is sized for the weight of the components (trolleys, etc.) and a dynamic load of up to $16,000 \mathrm{lb}$ with a center span deflection of less than 0.5 in.

The system is used to deploy a diverse set of tools that support waste retrieval efforts. Primary tools and their function are listed below.

The manipulators, which are mounted to base of the z-mast assemblies of the crane, are capable of dexterous and flexible movement in both teleoperated and robotic operation modes. They are used to sling, pick up, and move objects (up to $200 \mathrm{lb}$ at full 78-in. extension), work with the crane hook, work with each other, provide extra camera views, or hold lights on objects for enhanced visualization. The manipulators, with appropriate tools, are capable of digging in soil, if required, to support surgical retrieval of objects.

The vacuum system is employed to provide for retrieval of hazardous materials from the zone of environmental concern. The vacuum is an ideal system for retrieval of materials without generation of airborne particles and for mobilization of soil away from an article to be retrieved. Use of an experimental unit has generated retrieval rates of approximately $8,000 \mathrm{lb} / \mathrm{hr}$ of $1-1 / 2$-in. diameter rock, pea sized gravel, sand, and soil (retrieval rates vary somewhat dependant on the medium being vacuumed). The unit tested was rated at $40 \mathrm{hp}, 18 \mathrm{in}$. of mercury vacuum pressure, and had a 4-in.-diameter hose. During vacuuming exercises, vacuum pressure did not exceed 3 in. of mercury for any item being vacuumed. During the FY-95 summer integrated field test, the vacuum system will be designed to include a system that will break up hard packed soil.

A hydraulically opened and closed grapple assembly will be employed for the FY -95 summer field test. This device will be hung from the crane hoist and used for removal of soil or retrieval of objects from the waste pit. The grapple is configured as a large clamshell and can encompass a horizontal 55-gal drum without damage.

An integrated transfer module (ITM), which was demonstrated in September 1994, consists of a front-loading excavator shovel that also acts as a waste container. This concept will be adapted for use from the crane hoist hook for the FY-95 summer field test. The ITM may be filled by the vacuum system or have objects placed directly into it with either of the manipulators, 
and then placed into a waste conveyance system that will take the waste to an offloading station and return with an empty ITM.

The gantry system will deploy a number of geophysics instruments from the bottom of the z-mast (and/or a manipulator) to perform characterization of the hazardous area being surveyed. Planned for deployment in FY-95 are metal detectors, magnetometers, volatile organic compound (VOC) sensors, impulse radar, and possibly radiation detectors (dependant on source availability).

\subsection{Technology Need}

The DOE complex, other government agencies, and private industries have considerable volumes of buried waste. These sites contain wastes from DOE research, development, and production activities. The wastes buried at these facilities are classified as low-level radioactive waste (LLW), TRU, hazardous waste, mixed LLW, mixed TRU, and Greater-Than Class C (GTCC) waste. In addition, many of the waste containers have degraded and the soil immediately surrounding the waste is often contaminated. Because of the conditions of the waste sites, current environmental regulations, multiparty agreements, and DOE policy, these sites must be remediated. Furthermore, degraded and fragile waste containers pose a threat of contamination spread and increase the difficulty of the retrieval process. However, manual operations of retrieval and characterization equipment at a hazardous or radioactive site is potentially dangerous.

Remote retrieval and characterization systems will aid in the environmental restoration of DOE buried waste sites contaminated with hazardous and radioactive material. The characterization and retrieval capabilities provided by the CTR system keep equipment operators and other personnel at a safe distance from hazardous and radioactive materials. Not only does the system provide a safe alternative to conventional remediation methods, but it also reduces overall remediation costs and improves the rates at which conventional (manual) characterization in radioactive and other hazardous environments can be performed. Robotic deployment of characterization equipment also improves the positional accuracy of buried waste characterization data by providing very accurate positional data.

In some cases, the OTD buried waste program evaluates, demonstrates, and validates technologies and transfers this information and equipment to DOE and private industry to support remediation planning and implementation. This demonstration meets ER and WM needs for the following DOE sites: DOE-Albuquerque (AL), DOE-Chicago (CH), DOE-Idaho (ID), DOE-Nevada (NV), DOE-Oak Ridge (OR), DOE-Rocky Flats (RF), and DOE-Savannah River (SR). Table 1 shows potential application sites for this technology once it has finished the development and testing stages. Data in the table were extracted from multiparty agreements and the Technology Needs Crosswalk Report. ${ }^{1}$ The table is not a complete listing of the waste sites that could benefit from this technology. Table 1 identifies waste sites at various DOE facilities that have been identified as candidates for application of a telerobotic system in support of various $E R$ and WM activities. 
Table 1. Potential ER/WM application.

\begin{tabular}{llllllll}
\hline & \multicolumn{6}{c}{ Department of Energy Site } \\
\cline { 2 - 7 } Technology & \multicolumn{1}{c}{ AL } & CH & \multicolumn{1}{c}{ ID } & NV & \multicolumn{1}{c}{ OR } & RF & SR \\
\hline Cooperative & MDA & BNL & WAG OUs & SIW1 & WAG 5 & OU-2B & ORWGB \\
Telerobotic & RSITE & & $1-3,6$ & SIW2 & Bear & OU-9P & \\
Retrieval & TA2 & & $3-11$ & & Creek & & \\
& & & $7-10,13$ & & (OU-1) & & \\
& & & $10-$-soils & & & & \\
\hline
\end{tabular}

\subsubsection{DOE-AL MDA-Material Disposal Areas}

This area consists of buried material contaminated with metals, organics, LLW, and TRU. The buried waste may include pressurized gas cylinders. There is a significant volume of waste and undefined boundaries. Materials were randomly placed. The remedial action is scheduled for the years 2005 to 2012.

\subsubsection{DOE-AL RSITE-Random Sites}

This contaminated soil is probably mixed waste with possible organics, metals, TRU, LLW, and highly explosive materials. The remedial action is scheduled to be conducted during the years 2005 to 2012.

\subsubsection{DOE-AL TA2-Tech Area 2 Landfill}

This buried material is contaminated with organics, inorganics, and radionuclides (type questionable) and is in a former weapons assembly area. Some liquids were also buried. There is a large volume of waste in an undefined landfill boundary. Characterization is scheduled to be completed by the year 2000 .

\subsubsection{DOE-CH Brookhaven National Laboratory (BNL)}

Upon successful demonstration of the CTR system in the FY-95 summer integrated field test, the system will be considered for use at four waste pits at Brookhaven National Laboratory (BNL) in FY-96. The pits are round and approximately 12 to $15 \mathrm{ft}$ in diameter and $15 \mathrm{ft}$ deep. There are pesticides, containerized liquids, fluorescent light bulbs, cable, fence posts, drums, animal bones, concrete blocks, etc., in the pits. Little radioactivity is expected, but there is a potential for explosion.

\subsubsection{DOE-ID Waste Area Group (WAG), Operable Unit (OU) 1-3}

This operable unit consists of four sites: two burn pits, a laboratory bottle disposal site, and a gasoline spill from a service station. Soil in the pits is contaminated with metals and organics resulting from burning trash and waste organic compounds that occurred through the mid-1960s. 


\subsubsection{DOE-ID WAG, OU 1-6}

This operable unit consists of four old spill and disposal sites, including a 5,000-gal diesel spill, a 10-gal sulfuric acid spill, a 1-gal mercury spill, and a disposal pond for sanitary and process wastes, which could contain radionuclides, metals, and various chemicals.

\subsubsection{DOE-ID WAG, OU 3-11}

This operable unit consists of two sites: CPP-621 chemical storage area spills and CPP-PEW evaporator overhead pipeline spills. The major contaminants of concern are radionuclides, nitric and hydrofluoric acid, and heavy metals.

\subsubsection{DOE-ID WAG, OU 7-10}

This operable unit is an inactive disposal pit, Pit 9, located in the northeastern corner of the RWMC Subsurface Disposal Area. The waste within Pit 9 is primarily TRU and hazardous waste generated at the Rocky Flats Plant and additional waste from waste generators at the INEL. The waste consists of drums of sludge, drums of assorted solid waste, cardboard boxes containing empty drums, an inactive reactor vessel, and other large contaminated metal objects.

\subsubsection{DOE-ID WAG, OU 7-13}

This operable unit is defined as the pits and trenches containing TRU-contaminated waste at the RWMC Subsurface Disposal Area. These wastes include TRU, LLW, and mixed waste in solid and liquid form. Soils around or beneath the pits and trenches contaminated by the TRU and hazardous wastes are also included in the operable unit.

\subsubsection{DOE-ID WAG 10-Soils}

This operable unit consists of low-level radioactively contaminated soils across the INEL. Soils were contaminated mostly by wind blown contamination and spills of radioactive chemicals. The INEL is considering several types of treatments for the soils including physical, chemical, and biological treatments. The contaminated soils across the INEL were lumped into one operable unit to facilitate their effective evaluation and cleanup.

\subsubsection{DOE-NV SIW1-Sumps and Injection Wells}

These sites consist of mixed waste disposed of in shallow pits, craters, and trenches. Contaminants include $\mathrm{H}_{3}, \mathrm{Pu}, \mathrm{Cs}-137, \mathrm{Sr}-90$, I, heavy metals, solvents, and potentially polychlorinated biphenyls (PCBs). The volume of waste is unknown, however, there are 18 sumps and injection wells in seven areas. There is a potential for groundwater contamination. The Remedial Investigation/Feasibility Study (RI/FS) is scheduled to be completed in FY-97.

\subsubsection{DOE-NV SIW2-Eighteen Sumps and Injection Wells}

These sites consist of mixed waste disposed of in shallow pits, craters, and trenches. Contaminants include $\mathrm{H}_{3}, \mathrm{Pu}, \mathrm{Cs}-137, \mathrm{Sr}-90$, I, heavy metals, solvents, and potentially PCBs. The 
volume of waste is unknown, however, there are 18 sumps and injection wells in seven areas. There is a potential for groundwater contamination. The RI/FS is scheduled to be completed in FY-97.

\subsubsection{DOE-OR WAG 5}

ORNL WAG 5 is comprised of 16 contaminated sites, including LLW transfer lines and leak sites, hydrofracture surface facilities, waste storage tanks, a sludge basin and a holding pond, a shallow land burial ground containing radioactive and hazardous wastes [Solid Waste Storage Area (SWSA 5)], and a TRU waste storage area.

These sites are located east of White Oak Creek, between SWSA 4 and Melton ranch. SWSA 5 is a fenced area of about 80 acres and was used for disposing of routine buried waste (south side) and TRU-contaminated waste (north side). The major contaminants detected in ground waste seepage are $\mathrm{Sr}-90$ and $\mathrm{H}_{3}$.

\subsubsection{DOE-OR Bear Creek, OU-1}

Bear Creek OU-1 is comprised of the following units: S-3 Ponds, Sanitary Landfill I, Boneyard/Burnyard, the Oil Landfarm, and the Bear Creek Burial Grounds, including Oil Retention Ponds 1 and 2. These units were used until the 1980s as the primary area for the disposal of various types of hazardous and nonhazardous wastes generated at the Y-12 Plant.

The S-3 Ponds were constructed in 1951 and consisted of four unlined surface impoundments covering an area of roughly $400 \mathrm{ft}$ on each side with a total storage capacity of about 10 million gal. During its operation, up to 5,500 gal/day of effluent was pumped to the pond. The S-3 Ponds underwent Resource Conservation and Recovery Act (RCRA) closure in 1988. Primary contaminants were nitrates and uranium, with lesser concentrations of heavy metals and organic solvents.

Sanitary Landfill I received various types of nonhazardous waste from the Y-12 Plant. Waste disposal at Sanitary Landfill I was terminated in 1982, and the site was graded, capped, and closed in 1983.

The Boneyard/Burnyard consists of approximately 8 acres used from 1943 to 1970 as a disposal site for the waste from the Y-12 Plant. Burning and disposal of debris and sanitary, metallic, chemical, and radioactive wastes are known to have occurred. The site has been abandoned and is predominantly covered with grassy vegetation. The southeastern portion of this site is overlain by the Hazardous Chemical Disposal area, not considered to be part of the Boneyard/Burnyard. The Hazardous Chemical Disposal area is approximately 2 acres in size and was used to burn or neutralize liquid and gaseous wastes from 1975 until 1981. The Hazardous Chemical Disposal area is presently covered with a RCRA-type cap.

The Oil Landfarm was used for the land application of waste oils and coolants that contained beryllium compounds, depleted uranium, PCBs, and chlorinated organic compounds. Disposal operations were discontinued in 1982. Final RCRA closure of the site was certified by the Tennessee Department of Environment and Conservation in December 1990. 
The Bear Creek Burial Grounds Waste Management Area, located on the southern slope of Pine Ridge approximately 2 miles west of the Y-12 Plant, comprises a series of waste disposal units covering an area of about 5,000 by $3,000 \mathrm{ft}$. Each disposal unit consists of a series of trenches excavated to depths of 14 to $25 \mathrm{ft}$ belowgrade. The trenches received a variety of hazardous and nonhazardous solid and liquid wastes. All hazardous waste disposal operations were discontinued in 1981. All trenches known to have received RCRA hazardous material have been capped as part of a RCRA closure. Oil Retention Ponds 1 and 2 were constructed to intercept seepage from burial trenches. Both ponds were RCRA-closed in 1990. A wide range of contaminants may have been disposed of in the Bear Creek Burial Grounds. VOCs in oil resulting from groundwater transport are of primary concern.

The nature and extent of soil contamination within each of the listed units in Bear Creek OU-1 and the nature and extent of sediment and surface water contamination within each associated tributary to Bear Creek will be determined during the Comprehensive Environmental Response, Compensation, and Liability Act (CERCLA) investigation.

\subsubsection{DOE-RF OU-2B-903 Pad}

This area consists of several trenches that were used for burial of drums containing depleted $\mathrm{U}, \mathrm{Pu}$, and machining oils; radioactive contaminated crushed drums; and sanitary sewage sludges. There are approximately $10,000 \mathrm{yd}^{3}$ of buried material, including $25,000 \mathrm{~kg}$ of depleted uranium chips and $125,000 \mathrm{~kg}$ of sewer sludges. The concentrations include $\mathrm{Pu}$ at $55 \mathrm{pCi} / \mathrm{L}, \mathrm{U}$ at $1.2 \times 10 \mathrm{E} 6 \mathrm{pCi} / \mathrm{L}$, and VOCs in the $100 \mathrm{~s}$ of $\mathrm{ppb}$. The remedial action decision is required by 1995.

\subsubsection{DOE-RF OU-9P_Original Process Waste Lines}

This site consists of $35,000 \mathrm{ft}$ of pipe in, around, and under process buildings, many crossed by other utility lines. The pipes are contaminated with VOCs, all Rocky Flats radionuclides, nitrates, and mixed waste pesticides. No schedule was provided.

\subsubsection{DOE-SR Old Radioactive Waste Burial Ground (ORWBG)}

The ORWBG comprises a disposal area for solid radioactive waste produced at SRS, as well as shipments from other DOE and Department of Defense (DOD) facilities. The ORWBG, designated Building 643-E, has a quadrilateral shape and occupies approximately 75.8 acres. The nearest SRS boundary is over 6 miles to the north. The ORWGB began receiving waste in 1952 and was filled in 1972. The ORWBG has received no additional waste material since 1972.

The ORWBG was divided into sections to accommodate disposal of various levels/types of waste radioactive materials. These materials include TRU, LLW, and intermediate-level waste generated at SRS; and waste generated elsewhere. Examples of the materials disposed of at the ORWBG include the following:

- Incidental waste from laboratory and production operations (small equipment, spent air filters, clothes, analytical waste, decontaminant residues, plastic sheeting, gloves, soil, and construction debris) 
- Contaminated equipment (obsolete or failed tanks, pipes, jumpers, and other process equipment from the radiochemical separations area)

- Lead (lead shielding, equipment, shot, bricks, and sheets)

- Reactor hardware (fuel components and housings not containing irradiated fuel)

- $\quad$ Spent deionizer resins

- Spent lithium-aluminum targets (the waste target alloy after tritium has been extracted)

- Irradiated process oil from pumps in the tritium facilities and reactor areas (before bulk storage was started, the oil was placed in drums containing an absorbent material and buried)

- Mercury from gas pumps in tritium facilities (before 1968 , radioactively contaminated mercury was buried in 1 liter polyethylene bottles contained within a $0.7-\mathrm{ft}^{3}$ steel can)

- Cadmium (associated with control rods and neutron shielding sheets)

- Scintillation fluid (a mixture of organic solvents used to quantify low levels of radioactivity in environmental and bioassay samples)

- Shipments from off site (for example, radioactive waste from military hardware).

Earthen trenches for containing waste in the ORWBG were excavated $20 \mathrm{ft}$ wide, $20 \mathrm{ft}$ deep, and up to $700 \mathrm{ft}$ long. Trenches were covered with $4 \mathrm{ft}$ or more of soil to reduce surface radiation to less than $6 \mathrm{mR} / \mathrm{hr}$. Beginning in 1962, records were kept of the contents, radiation level, and approximate storage location of each shipment of waste. Later, this information was retroactively recorded, from existing written burial records and from the recollection of operating personnel, into the Computerized Radioactive Waste Burial Records Analysis (COBRA) system for future reference. Many of the waste volumes and radionuclide quantities were estimated, including information on waste disposed prior to 1962 . The location of the burial/storage area for each shipment of waste was defined by a 100-ft grid system laid out in 1962 . These grids were further divided into 20 -ft squares.

Until 1965, TRU waste contained within plastic bags and cardboard boxes was buried in unlined trenches designated specifically for this waste. Between 1965 and 1972, TRU waste was segregated according to TRU material content. Waste containing less than $0.1 \mathrm{Ci}$ per package was buried unencapsulated in alpha trenches. Waste containing greater than $0.1 \mathrm{Ci}$ per package was buried in retrievable concrete containers $6 \mathrm{ft}$ in diameter and $6.6 \mathrm{ft}$ high. Waste that did not fit into the prefabricated concrete containers was encapsulated in place in concrete. The inventory of radioactive waste buried nonretrievably in the ORWBG is listed in the RCRA Facility Investigation/Remedial Investigation (RFI/RI) Work Plan and includes fission products, induced activity, other, depleted uranium, enriched uranium, U-233, Np-237, Pu-238, Cm-244, californium, weapons grade plutonium, normal uranium, thorium, and tritium. 
Burials of TRU waste generated elsewhere have occurred in the ORWBG. A collision in 1966 between a bomber carrying nuclear weapons and a refueling plane contaminated the ground at Palomares, Spain, with plutonium. Cleanup of the site produced 4,827 55-gal drums of soil and vegetation containing an estimated 90 curies of Pu-239. In 1966, these drums were placed in the ORWBG in two separate trenches having a cumulative length of $600 \mathrm{ft}$. The average TRU concentration was estimated to be $48 \mathrm{nCi}$ per gram of waste form in the drums. In 1968, a bomber carrying nuclear weapons crashed in Greenland, producing large quantities of contaminated ice and aircraft parts. Recovery activities produced 535 containers with a total volume of approximately $123,000 \mathrm{ft}^{3}$ of aircraft parts. It also produced tanks of approximately 630,000 gal of water potentially contaminated with Pu-239. The waste was processed, and the empty tanks and aircraft parts were buried in three separate trenches in the ORWBG. Very low levels of TRU contamination were detected on this material, which is considered as low-level, alpha-emitting waste.

Inorganic constituents, such as lead (used to shield a variety of waste forms or discarded used to high contamination levels) and cadmium (from control rods, safety rods, and shielding) were placed in the ORWBG. Various solvents, including naphthalene, toluene, tributylphosphatekerosene, trimethylbenzene, and xylene, were stored in 22 underground storage tanks at the ORWBG. These tanks have since been emptied and a closure plan for the tanks was to be prepared in 1993. Several of the tanks contain highly radioactive sludge. The quantities of the various metals and solvents reported to have been buried at the ORWBG include cadmium, lead, mercury, n-Dodecane, naphthalene, toluene, tributylphosphate, trimethylbenzene, and xylene. One trench in the east-central part of the ORWBG approximately $100 \mathrm{ft}$ long was used for disposal of an unknown quantity of empty oil drums.

\subsection{Other Related Work}

A discussion of related work follows. Section 1.6.1 addresses related projects that have equipment that must be deployed from the crane or interface with the crane for the FY-95 summer integrated field test. Section 1.6.2 discusses related external work and explains the differences between our work and the related work.

\subsubsection{Other OTD Buried Waste Projects}

The CTR system has been developed to successfully deploy multiple tools. During this demonstration, the crane was manipulated to perform scan paths, thereby simulating characterization surveys. In addition, the crane deployed a vacuum system to retrieve various objects.

In the summer of FY-95, the CTR system will be responsible for deploying a variety of equipment that was developed and will be field tested with OTD buried waste funds. The following projects will have equipment to be deployed off of the gantry crane: Digface Characterization and Holographic Impulse Radar Array.

In addition to deploying various tools, the remote gantry crane will interface with other OTD buried waste technologies. The Remote Conveyance System and ITMs will be implemented to work closely with the gantry crane to accomplish a simulated waste retrieval. 


\subsubsection{External Projects}

Various projects have been or are being performed to develop technologies related to the CTR project. The work discussed here falls into two categories: delivery mechanisms and dual manipulators.

The gantry crane, used to support the CTR project, was selected as the result of value engineering sessions held with project stakeholders. For other applications, different delivery platforms may be more suitable. The National Institute of Standards and Technology (NIST) has developed a Stewart platform that may have application to some remediation scenarios. The NIST platform consists of a tripod structure that is used to suspend a work base between the tripod legs. NIST has developed a control system to effectively control the position and orientation of the work base.

Oak Ridge National Laboratory (ORNL) and Sandia National Laboratories (SNL) have developed technologies to assist in the automation of cranes. An area of interest to the CTR program that is currently implemented at ORNL and SNL is the "swing free" payload movement. This technology controls the velocity and acceleration of the crane to offset the pendulum-motion of the hook normally seen when moving payloads.

Numerous agencies are working on control methodologies to enhance the effectiveness of dual manipulators. RedZone Robotics recently delivered a dual manipulator system to ORNL for decontamination and decommissioning activities. Both manipulators are mounted on a base in a way that allows each manipulator independent rotation and translation. Carnegie Mellon University is developing "Rosie," a robotic vehicle with a telescopic boom that deploys dual manipulators. SNL is researching the coordinated control aspect of the dual electric manipulators system. Coordinated control allows both manipulators to jointly hold a pipe and move it through the work space. Stanford University has had impressive results with coordinated control of a dual manipulator system. In contrast the CTR system currently implements cooperative control, which allows one manipulator to hold a pipe while the other manipulator cuts the pipe.

\subsection{Technology Commercialization and Implementation}

There are three primary objectives for technology commercialization and implementation. The first objective is transferring existing and emerging technology from industry, universities, and other federal agencies for integration with developing technologies. This is called technology infusion or partnering. The second objective is sharing technologies with other DOE laboratories through integrated demonstrations. This is called technology adoption or ER/WM implementation. The third objective is transferring the demonstrated technologies to private industry. This is called technology diffusion or commercialization.

The CTR project has worked with American Crane and Equipment Corporation (ACECO) to develop a crane that meets the needs ER/WM. This crane was purchased based on specifications developed by the project team and the need for a platform to deliver equipment used to remotely characterize and retrieve buried waste. The project also purchased two Titan II robotic manipulators from Schilling Development. In addition, the project purchased an off-the-shelf systems controller from Cimetrix. The project team and Cimetrix worked together to expand the 
applicability of the controller, enhance its capabilities, and work out "bugs." This work mutually benefitted both Cimetrix and the project. Thus, industrial interfacing has aided technology infusion and diffusion. The CTR system represents the integration of a multitude of commercially available, as well as state of the art products. The integration is utilizing these technologies to perform tasks and operations that are beyond the original vision for their use.

Technology adoption is in process. The system's initial test results are documented in this report, and a full-scale integrated test demonstration of the crane (the next step in technology adoption) is planned for the summer of 1995 . Finally, there are plans to potentially take the system to BNL (see Section 1.5) to aid in the remediation of four hazardous waste pits.

Once development is closer to completion, technology diffusion of the cooperative telerobotic manipulator system will be pursued. Licensing the technology to private industry could provide ER/WM with a powerful resource. 


\section{TEST OBJECTIVES}

\subsection{Purpose of Tests}

The purpose of the CTR project was to test and demonstrate the capabilities of the system. The delivery system was tested for precision and repeatability of positioning at several speeds. Both cooperative and independent movement were demonstrated. Delivery of a vacuum and digface characterization equipment was demonstrated. Video interfaces were evaluated. Environmental effects and system deficiencies were documented. These data will be used in planning for the FY-95 summer integrated field test.

\subsection{Test Objectives and Data Quality Objectives}

The objective of this demonstration was to test the implementability, effectiveness, and cost of the CTR equipment that will be used to support the FY-95 summer integrated field test. The system will ultimately support the remediation of waste sites.

The test objectives identified in Cooperative Telerobotic Retrieval Test Plan for Fiscal Year 1994 are restated here. ${ }^{2}$ The tests performed were divided into key and non-key objectives. Key objectives were objectives that were considered important to the successful demonstration and evaluation of the system in preparation for FY-95 activities. Non-key objectives were to provide useful information but not considered critical to the evaluation of the system.

\subsubsection{Key Objectives}

\subsubsection{Delivery System.}

Test Objective: $\quad$ Demonstrate that the crane can be moved in space in a controlled manner, and determine the precision, accuracy, and repeatability of the movements to two separate locations in space at four speeds $(100,75$, 50 , and $25 \%$ of capacity).

Data Quality Objective: Determine with a 95\% confidence level that for any target movement, the variation from expected position in the $\mathrm{x}, \mathrm{y}$, and $\mathrm{z}$ local coordinate system is no greater than $\pm 1 \mathrm{in}$. along each axis at any of the four speeds tested.

Test Objective: $\quad$ Demonstrate the ability of the system to move along the $\mathrm{x}, \mathrm{y} 1, \mathrm{y} 2, \mathrm{y} 3$, $\mathrm{z} 1, \mathrm{z2}$, and $\mathrm{z} 3$ directions at four speeds $(100,75,50$, and $25 \%$ of capacity).

Data Quality Objective: Determine the commanded versus actual speed of movements in the $x$, $\mathrm{y} 1, \mathrm{y} 2, \mathrm{y} 3, \mathrm{z} 1, \mathrm{z} 2$, and $\mathrm{z} 3$ directions in feet per minute. 


\subsubsection{Independent Movement.}

Test Objective: Demonstrate the ability of the equipment to operate in an independent fashion. Independent movement shall be demonstrated for two manipulators. Document that the system can achieve independent movement by accomplishing a task involving manipulation of the Schilling manipulators to perform two unrelated tasks simultaneously using two operators and photographic evidence.

\subsubsection{Cooperative Movement.}

Test Objective: Demonstrate the ability of the equipment to operate in a cooperative fashion. Document that the system can achieve cooperative movement by accomplishing three tasks involving cooperative movement, and photographic evidence.

\subsubsection{Deployment of Tools.}

Test Objective: Demonstrate the ability of the equipment to deploy a vacuum.

Data Quality Objective: Document that the system can successfully deploy a vacuum by vacuuming wet and dry soil as well as small debris. Determine the size of the largest debris the vacuum can retrieve (compared to published capability). Determine the speed $\left(\mathrm{ft}^{3} / \mathrm{min}\right)$ of remote and manual vacuuming.

Test Objective: $\quad$ Demonstrate that the digface characterization equipment can be moved in space in a predetermined and controlled manner. Document that the system can follow a path programmed using the planar path planning algorithms, by accomplishing a survey and photographic evidence.

\subsubsection{Failures, System Deficiencies, and Maintenance.}

Test Objective: Demonstrate the ability of the equipment and processes to operate.

Data Quality Objective: Document the system failures by documenting the number of failures, the nature of the failure, the time required to fix the component/system, what the "fix" entailed, configuration changes, and the cost of the "fix." In addition, any deficiencies that appear in the software, crane, tools, interface, etc., will be documented. Document the routine maintenance activities by recording what materials were used and the time taken to perform the maintenance. 


\subsubsection{Non-Key Objectives}

\subsubsection{Environmental Effects.}

Test Objective: Evaluate the system for operation in the environment. Document the environmental effects on the system during operation by determining any operational problems due to wind, temperature, and/or precipitation.

\subsubsection{Cost Baseline and Schedule Data.}

Test Objective:

Test Objective:

Test Objective:

Test Objective:

Data Quality Objective:
Establish the system cost baseline. Document the costs associated with the development, operation, and maintenance of the system.

Evaluate the system's implementability. Document the time required for erecting the crane, checking the crane out, and performing retrieval of buried wastes, using various small tools and the vacuum. Also document the number of personnel required to operate and maintain the system, and document support equipment required during the crane setup and during testing.

Demonstrate the rate of soil and debris removal (as performed during the demonstration) by measuring the time of the actual retrieval operations and the volume (in cubic yards) of soil and debris removed. Document the performance of the selected vacuum system for operation duration, volume collected, and type of materials collected.

Evaluate the operator's ability to program a scan path and execute that path.

Document the ability of the operator to perform a scan path during the demonstration by measuring the time of actual programming and execution times within \pm 10 seconds.

\subsubsection{Human-Computer and Human-Video Interfaces.}

Test Objective: $\quad$ Evaluate the system's human-computer and human-video interfaces. Document the camera views that the operators used the most. Also document operators' opinions about the usefulness of the displays and associated software.

Test Objective: $\quad$ Evaluate the four tracking cameras for three different situations involving both static and dynamic targets. 
Data Quality Objective: Demonstrate the cameras' ability to track both static and dynamic targets. This will be accomplished several ways. Document the operators' thoughts on the performance of the cameras. Measure both the time per minute that the video display for each camera does not show the object of interest. Measure the number of times the object is out of focus or too small or large on the screen. 


\section{EXPERIMENTAL DESIGN AND PROCEDURES}

CTR system tests were performed at the NBA. The tests were repeated as necessary to acquire meaningful data. General descriptions of each test follow, while detailed test information is provided in Appendix A. Test results can be found in Section 7.

\subsection{Test Descriptions}

\subsubsection{Key Objectives}

3.1.1.1 Delivery System. The precision and accuracy of positioning the $x$ axis (crane on rails), $\mathrm{y} 1$ axis (Trolley $\mathrm{A}$ across the girder), $\mathrm{z} 1$ axis (Trolley $\mathrm{A}$ mast telescoping up and down), and a combination of movement of the three axes (xy1z1) were determined at four speeds (100, 75, 50 , and $25 \%$ of capacity). The test moved each axis to a location in space, and measured the difference between the location the axis was commanded to go and the location the axis actually traveled to, using surveyors instruments and a local coordinate system. Home position for the $\mathrm{x}$-axis is approximately $1 \mathrm{ft}$ east of the limit switch on the west end of the rails. The $y 1$-axis home position was defined as approximately $1 \mathrm{ft}$ north of the limit switch on the south end of the girder. Finally, the z1-axis home position was defined as about $1 \mathrm{ft}$ above the limit switch for extension.

The commanded versus actual speed was also determined during testing. Table 2 shows the commanded speeds at which each axis was tested. Commanded speeds were limited based on Robline control from what could actually be accomplished per the design specifications. Stop watches were used to determine the actual speeds at which the axes moved. In order to effectively determine the speeds, the point in space that each axis moved to was a minimum of $x=25, y=25$, and $z=3 \mathrm{ft}$ from a position defined as the home position $(x=0, y=0, z=0)$. The tests were performed for the locations shown in Table 3. Initiation of each movement was from the home position. Each single axis test was performed five times and the multiple axes movement test was repeated three times. See Section 7.1 for results.

Table 2. Crane speeds that were tested.

\begin{tabular}{lcccc}
\hline \multicolumn{5}{c}{ Commanded speeds } \\
\cline { 2 - 5 } Axis & $\begin{array}{c}100 \% \\
(\mathrm{ft} / \mathrm{min})\end{array}$ & $\begin{array}{c}75 \% \\
(\mathrm{ft} / \mathrm{min})\end{array}$ & $\begin{array}{c}50 \% \\
(\mathrm{ft} / \mathrm{min})\end{array}$ & $\begin{array}{c}25 \% \\
(\mathrm{ft} / \mathrm{min})\end{array}$ \\
\hline $\mathrm{x}$ & 30.1 & 22.6 & 15.1 & 7.5 \\
$\mathrm{y} 1$ & 23.1 & 17.3 & 11.6 & 5.8 \\
$\mathrm{z} 1$ & 7.5 & 5.6 & 3.8 & 1.9 \\
\hline
\end{tabular}


Table 3. Target locations.

\begin{tabular}{lc}
\hline Axis & $\begin{array}{c}\text { Location } \\
(x, y, z)\end{array}$ \\
\hline$x$ & $300,0,0$ in. \\
$y 1$ & $0,300,0$ in. \\
$z 1$ & $0,0,36$ in. \\
$x y 1 z 1$ & $100,100.36$ in. \\
\hline
\end{tabular}

3.1.1.2 Independent Movement and Deployment of Tools. The independent movement and deployment of tools tests were combined as discussed in the test plan. By using the two manipulators to deploy a simulated digface characterization sensor suite and a monitoring camera simultaneously, independent movement was successfully demonstrated. This test was performed four times.

The simulated digface characterization sensor suite was held in the jaws of Manipulator 1. A video camera was held in the jaws of Manipulator 2. The time to plan a path by choosing three points and then executing the scan was recorded. The raster scan area encompassed a $10 \mathrm{ft}$ by $10 \mathrm{ft}$ area in the $\mathrm{x}-\mathrm{y}$ plane. A video record was made of the scan and monitoring during the test.

The vacuum was tested three additional ways. The first test involved manually operating the vacuum to retrieve an array of objects including: office supplies such as paper, pencils, rubber gloves, crushed pop cans, paper clips, etc; 1 gal of vegetable oil; 3 gal of sand; 3 gal of soil; 3 gal of gravel; and 3 gal of 1-1/2-in. rock. Target retrieval time was recorded for comparison with subsequent remote vacuum retrieval of sand, gravel, and rock.

The second vacuum test involved using the vacuum nozzle manually secured to the $\mathrm{z} 1$-mast to retrieve the same targets: sand, gravel, and 1-1/2-in. rock. The capability of the vacuum and the time to retrieve each target was recorded in the same manner as the manual vacuum test.

An additional vacuum test was demonstrated by deploying the vacuum from the $\mathrm{z1}$-mast and vacuuming large sand, gravel, and 1-1/2-in. rock piles. A scan path was set and was executed at two different elevations (i.e., $z$ offsets) for each pile. A video was taken to document the performance achieved by the vacuum for this type of test. See Section 7.2 for results.

3.1.1.3 Cooperative Movement. Cooperative movement was demonstrated using three operating scenarios. The first operation involved rigging and moving an oversized object. This entailed coordinated movement of the two manipulators and the hoist. The second operation involved tracking an object with a camera. This operation entailed moving an object with one manipulator and tracking that movement with a camera held by the second manipulator. The third operation involved one manipulator handing an object to the second manipulator. Success was based on accomplishment of the tasks and was not dependent on the time it took to accomplish the task. See Section 7.3 for results. 
3.1.1.4 Failures and System Deficiencies. All failures were recorded in logbooks. Measurement parameters included documenting the number of failures, the nature of the failure, the time required to fix the component/system, what the "fix" entailed, its cost, and configuration changes. In addition, any deficiencies that appeared in the software, crane, tools, interface, etc., were recorded in logbooks and are identified in Section 9. Routine maintenance operations (RMOs) were not required. See Section 7.4 for results.

\subsubsection{Non-Key Objectives}

3.1.2.1 Environmental Effects. The environmental effects on the system were monitored and noted in the logbooks. Area weather conditions were monitored during testing, and any effects of the environment on the system were listed. Wind speed, temperature, and amount of rainfall/snowfall were recorded by the National Oceanic and Atmospheric Administration (NOAA) in Idaho Falls, approximately 2 miles from the testing location. See Section 7.5 for results.

3.1.2.2 Cost Baseline. An underlying goal of the CTR project is to move the technology into the commercial sector. To accomplish this task, cost of the system becomes a significant consideration. A representation of cost was determined by factoring all costs associated with the system, including development, operating, capital, and maintenance costs. This information is provided in Section 10.

3.1.2.3 Human-Computer/Video Interface. One important operator interface affecting the efficiency of operations is video. Previous tests demonstrate that using 2-D video systems have limited the operator's ability to move freely and operate in a 3-D environment. Because of the extensive industrial testing for vision, no tests were performed to evaluate the operator's ability to use the video data to move in space. Instead, the operators' opinions about the usefulness of the displays and associated software were recorded. See Section $\mathbf{7 . 6}$ for results. 


\section{QUALITY ASSURANCE}

\subsection{Internal Quality Control Checks}

\subsubsection{Measures Taken}

Company procedures for logbooks and data management were followed during testing at the INEL. Logbook data were recorded in ink and signed by the recorder. Data entry pages were verified and signed by someone other than the recorder.

Changes in test procedures were limited to those necessary to meet test objectives and were approved by the Principal Investigator (PI) per the "Test Plan Change" section. The effects of any changes on test objectives were minimized to the greatest extent possible. Procedures of altered tests were edited (see Section 4.4.2 and Appendix A).

\subsubsection{Effectiveness}

The field logbook was very effective for noting progress, changes, and problems encountered. It served as the repository of all data.

Certain test procedures required onsite modification. By allowing procedures to be redlined, the appropriate flexibility in testing allowed testing to continue in a reasonable manner and within a reasonable schedule.

\subsection{Document Control}

\subsubsection{Data Management}

All data were recorded in the bound laboratory notebook in accordance with company procedures. Data were recorded in ink and signed by the recorder, a witness, and a reviewer. All logs will be kept as part of the official project records and copies will be kept at the Robotics Center. See the LITCO Management Policies Manual (In Transition), formerly the EG\&G Idaho Resource Manual, for the policy on laboratory notebooks.

\subsubsection{Test Plan Changes}

A discussion of changes made to the test plan during testing follows.

Delivery system tests were modified from the original test plan due to schedule limitations. Delivery system tests were modified from going to two locations to going to one location. In addition, the tests were performed only on the $x, y 1, z 1$, and xy1z1 axes. The results should be transferrable to the $y 2, z 2$, and $x y 2 z 2$ axes because the systems are identical and all parameters are the same for these axes. The y3 and $\mathrm{z} 3$ axes (hoist) could not be tested because the positioning system was damaged (requiring extensive time to repair) and therefore could not be homed properly. These changes were redlined in the procedure to save time but still provide sufficient data to analyze the performance of the crane axes. 
Vacuum tests were modified from the original test plan to provide more meaningful results. The first vacuum test was performed manually with the originally planned objects and liquids. The times were recorded but were barely measurable because the vacuum has tremendous suction and would retrieve the objects in fractions of a second. Therefore, the tests were modified to repeatedly retrieve four targets: $3 \mathrm{gal}$ of sand, $3 \mathrm{gal}$ of soil, $3 \mathrm{gal}$ of gravel, and $3 \mathrm{gal}$ of 1-1/2-in. rock. Due to time limitations, the vacuum was not tested for the size of objects it could retrieve. The hose size was 4 in.

The human computer tests planned for camera tracking were not performed due to schedule limitations, but will be addressed prior to the FY-95 summer integrated field test.

\subsection{System Configuration Management}

During testing, the control software was modified as necessary to correct problems as they were encountered so that testing could continue. None of these changes affected any of the data. The application software has been baselined and all changes to that baseline have been documented in a software database. A new version of the Robline Server from Cimetrix Corporation was also installed during the testing period to correct existing deficiencies. The primary control computer had a disk failure during testing, so the software on that system had to be restored (including the Lynx operating system and all the configuration files and applications software). A backup disk was installed to reduce recurrence of this problem during future activities.

The following software changes are examples of the type of changes that were required for the testing to continue:

- The robotics model was changed to match the physical system for several of the robotics joints. Changed model values included positive joint movement direction, home positions, maximum speed, and joint limits. Changes of this type were expected and additional changes are expected as the system is fine tuned.

- Several changes were made to the control software to correct problems during simultaneous motion of mechanisms. The motion of one mechanism interfered with the motion of another mechanism.

- The initialization parameters for the PMAC servo-amp driver cards were modified to correct some of the tuning values. These parameters will also be adjusted during fine tuning of the system.

- The software that allowed path planning (three-point plane path generation software) was modified to provide for additional options. This allowed vacuuming tests to be done with the Schilling manipulators while the crane was inoperative.

- The controller Pentium processor board inside the system controller failed during the test and was replaced with an available 486 processor board. 
- The length of the rails was increased in the computer model.

- The exact placement and orientation of the limit switches was entered into the computer model. 


\section{HEALTH AND SAFETY}

All activities were performed in accordance with the Environmental, Safety, Health, and Quality Plan for the Buried Waste Integrated Demonstration Program. ${ }^{3}$

\subsection{Hazard Analysis}

Hazard classification determinations are required on all projects. The Deployment Team supports projects in obtaining hazard classification determinations by documenting the projects and obtaining Independent Safety Review Committee evaluations on those projects that require this level of review. The CTR activity was deemed "routinely accepted by the public."

\subsection{Employee Training}

Workers and project employees are required by company operating procedures to undergo safety training for activities within their respective work areas. Fire safety, lifting and moving of objects, and other job specific training was provided. Specific training activities are discussed below and were abstracted from Training Requirements and Responsibilities for the Buried Waste Integrated Demonstration at the Radioactive Waste Management Complex. ${ }^{4}$

The PI was responsible for ensuring that test and development personnel were properly trained in accordance with the following requirements:

- Training in lockout/tagout programs should be obtained if there is a potential for injury to personnel or equipment during equipment operation, servicing, maintenance, or modification activities. This need should be determined by the PI.

- Training shall include an examination to ascertain level of knowledge.

- Records of all training provided shall be kept in employee training records.

- Training on requirements/procedures for an equipment development area.

The PI and the lead technician are both fully trained and experienced in lockout/tagout procedures.

Listed below are other optional training courses that the PI took. All individuals operating or maintaining the equipment were under the direct supervision of the PI. This training was only optional since the crane was operated remotely/robotically and was used for Research and Development.

- Professional Overhead Crane and Rigging Training (triennial-40 hours) is required to operate the gantry crane (DOE Hoisting and Rigging Manual 2.0, paragraph 2.1.1). In

a. EG\&G Idaho Notegram from Don Ord to L. C. Rounds, June 9, 1994, and Interoffice Correspondence from B. E. Griebenow to L. C. Rounds, BEG-17-94, June 6, 1994. 
addition, OSHA requirements for the operation of cranes are contained in 29 CFR $1926.550(a)(b)(d)$ and 1910.178.

- The PI is authorized by "Incidental Crane Operators in Rigging Practices and Overhead Crane Operations" training (certification expires February 1, 1996).

\subsection{Health}

No serious personnel health problems occurred as a result of the CTR system tests. However, due to the cold temperatures and the need for personnel to move indoors and outdoors continuously during the tests, all but one of the test personnel became ill, including one case of walking pneumonia.

\subsection{Physical Safety}

The project operated under a safe work permit that was obtained on a weekly basis. The safety engineer conducted several safety walkthroughs of the area when tests were being performed.

Buried waste personnel and subcontractor personnel were responsible for complying with applicable sections of the company's Safety Manual, Industrial Hygiene Manual, RWMC Operational Safety Requirements Safety Analysis Report, Conduct of Operations Manual, and Environmental Restoration Program Generic Health and Safety Plan.

Physical safety entailed items such as signs, fences, and ropes. The immediate area around the gantry crane was roped off. The entire back area of the NBA is protected from intruders by a locked fence. Signs were posted warning personnel of the dangers if they entered the immediate area.

In addition, the roped area was declared an equipment development area. This designation encompasses research and development projects using prototype equipment. Troubleshooting, repair, modification, and redesign are research and development parameters for this class of equipment. The designation allows engineers and technicians who design the equipment to also work on the prototype equipment. Project team personnel were trained in procedures that control the designated area and were required to wear both hard hats and safety glasses while in the area.

\subsection{Emergency Response Plan}

The NBA is provided with approved, tested, and maintained warning systems. This system is tied into the INEL Communications Warning Center, the Idaho Falls fire and police departments, as well as the DOE Idaho Operations Office (DOE-ID). For FY-94, special communication systems were not required, since all work was performed at the NBA. Air monitoring was not required because no hazardous or potentially hazardous materials were used. 


\section{ENVIRONMENTAL OVERVIEW}

\subsection{National Environmental Policy Act}

Based on National Environmental Policy Act (NEPA) requirements, the environmental impact from this demonstration was minimal. Operations over the simulated waste resulted only in shortterm noise. Crane noise effects were negligible. The simulated waste was nonhazardous and nonradioactive and did not have a significant impact on the environment. This activity was covered under NBA facility umbrella Categorical Exclusion. ${ }^{b}$

\subsection{Occupational Safety and Health Administration}

Occupational Safety and Health Administration (OSHA) regulations affecting the testing and demonstration were limited because the CTR system is a remote system and activities were not performed in a hazardous or radioactive environment. Protective gear was supplied as deemed necessary by health and safety professionals and safe work permits covered activities during the demonstration. Access to the operating envelope was controlled per OSHA requirements. The simulated pit area was roped off as an equipment development area and no one was allowed to enter during operations.

\subsection{Waste Minimization}

The tests were performed at the NBA with nonhazardous and nonradioactive simulated waste. The CTR system itself does not generate waste other than used hydraulic fluid. However, the system was used to vacuum a variety of objects and soil mixtures. This nonhazardous waste was discarded in the INEL landfill.

\subsection{Environmental Issues During Testing}

There were no environmental issues during testing.

b. DOE-ID Memorandum from A. A. Pitrolo to Carol M. Borgstrom, Director of Office of NEPA Oversight, "Categorical Exclusion for the North Boulevard Robotics Complex Routine Activities for Remote Automation," AM/EP-ETD-ATB-93-45, March 2, 1993; and EG\&G Idaho Interoffice Correspondence from J. F. Graham to R. A. Hyde, "Cooperative Telerobotic Retrieval," JFG-01-94, January 5, 1994. 


\section{TEST RESULTS}

\subsection{Delivery System}

There were two test objectives for the delivery system. First, demonstrate that the axes can be moved in space in a controlled manner and determine the associated precision, accuracy, and repeatability of the movement at four speeds $(100,75,50$, and $25 \%$ of capacity). The corresponding data quality objective was to determine with a $95 \%$ confidence level that for any target movement, the variation from expected position in the $\mathrm{x}, \mathrm{y}$, and $\mathrm{z}$ local coordinate system is no greater than \pm 1 in. along each axis at any speed tested. The second objective was to determine the commanded versus actual speed of movements in the $\mathrm{x}, \mathrm{y} 1$, and $\mathrm{z} 1$ directions in feet per minute.

\subsubsection{Data and Data Reduction}

Delivery system tests were performed five times at four speeds for the individual $\mathrm{x}, \mathrm{y} 1$, and $\mathrm{z1}$ axis movement trials, and three times at four speeds for the combined xy1z1 axes. The crane was moved from the home position to a fixed specified location for each test. A summary of accuracies of speed and positioning in the $\mathrm{x}, \mathrm{y}$, and $\mathrm{z}$ directions for each speed is found in Tables 4-7. Each table presents the commanded speed, actual speed, speed error, and position error along the $\mathrm{x}, \mathrm{y}, \mathrm{z}$, and $\mathrm{xyz}$ axes. At the bottom of each table are the errors from combined data from all speeds. Appendix B gives the raw data from these tests.

Table 4. Summary of data for moving along $\mathrm{x}$ axis.

\begin{tabular}{|c|c|c|c|c|c|c|c|}
\hline Commanded & $\mathrm{ft} / \mathrm{min}$ & $\begin{array}{c}\text { Mean } \\
\text { actual } \\
\text { speed } \\
\text { (ft/min) }\end{array}$ & $\begin{array}{l}\text { Mean } \\
\text { speed } \\
\text { error } \\
(\mathrm{ft} / \mathrm{min})\end{array}$ & $\begin{array}{l}\text { Mean } \\
\text { position } \\
\text { error along } \\
x \text { axis } \\
\text { (in.) }\end{array}$ & $\begin{array}{c}\text { Mean } \\
\text { position } \\
\text { error along } \\
\text { y axis } \\
{\text { (in. })^{a}}^{a}\end{array}$ & 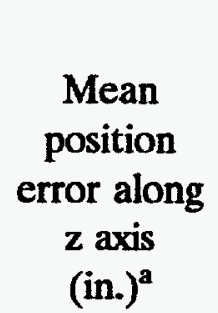 & $\begin{array}{c}\text { Mean } \\
\text { total } \\
\text { position } \\
\text { error } \\
\text { (xyz) } \\
\text { (in.) }\end{array}$ \\
\hline 100 & 30.1 & 30.1 & b & -0.67 & 0.01 & 0.08 & -0.68 \\
\hline 75 & 22.6 & 24.3 & 1.7 & -0.91 & -0.01 & 0.07 & -0.92 \\
\hline 50 & 15.1 & 17.1 & 2.1 & -0.76 & 0.06 & 0.05 & -0.77 \\
\hline 25 & 7.5 & 9.0 & 1.5 & -0.97 & 0.05 & 0.08 & -0.97 \\
\hline $\begin{array}{l}\text { Average of } \\
\text { all speeds }\end{array}$ & & $\mathbf{n} / \mathbf{a}$ & n/a & -0.83 & 0.03 & 0.07 & -0.84 \\
\hline
\end{tabular}
a. No move commanded on this axis.
b. NA. The $100 \%$ speed was used as the basis for the other expected speeds. 
Table 5. Summary of data for moving along yl axis.

\begin{tabular}{|c|c|c|c|c|c|c|c|}
\hline \multicolumn{2}{|c|}{ Commanded speed } & \multirow{2}{*}{$\begin{array}{c}\text { Mean actual } \\
\text { speed } \\
(\mathrm{ft} / \mathrm{min}) \\
\end{array}$} & \multirow{2}{*}{$\begin{array}{c}\text { Mean } \\
\text { speed } \\
\text { error } \\
(\mathrm{ft} / \mathrm{min})\end{array}$} & \multirow{2}{*}{$\begin{array}{c}\text { Mean } \\
\text { position } \\
\text { error } \\
\text { along } x \\
\text { axis } \\
\text { (in.) }^{\mathbf{a}}\end{array}$} & \multirow{2}{*}{$\begin{array}{l}\text { Mean } \\
\text { position } \\
\text { error } \\
\text { along y } \\
\text { axis } \\
\text { (in.) }\end{array}$} & \multirow{2}{*}{$\begin{array}{c}\text { Mean } \\
\text { position } \\
\text { error } \\
\text { along } z \\
\text { axis } \\
\text { (in.) }^{\mathbf{a}} \\
\end{array}$} & \multirow{2}{*}{$\begin{array}{c}\text { Mean } \\
\text { total } \\
\text { position } \\
\text { error } \\
\text { (x1z1) } \\
\text { (in.) }\end{array}$} \\
\hline$\%$ & $\mathrm{ft} / \mathrm{min}$ & & & & & & \\
\hline 100 & 23.1 & 23.1 & b & -0.10 & -0.76 & 0.08 & -0.79 \\
\hline 75 & 17.3 & 17.6 & 0.3 & -0.05 & -0.76 & 0.11 & -0.77 \\
\hline 50 & 11.6 & 12.1 & 0.6 & -0.05 & -0.81 & 0.10 & -0.82 \\
\hline 25 & 5.8 & 6.1 & 0.4 & -0.07 & 0.77 & 0.07 & -0.77 \\
\hline $\begin{array}{l}\text { Average of } \\
\text { all speeds }\end{array}$ & & $\mathrm{n} / \mathrm{a}$ & $\mathbf{n} / \mathbf{a}$ & -0.02 & -0.77 & 0.09 & -0.79 \\
\hline
\end{tabular}

a. No move commanded on this axis.

b. NA. The $100 \%$ speed was used as the basis for the other expected speeds.

Table 6. Summary of data for moving along $\mathrm{z1}$ axis.

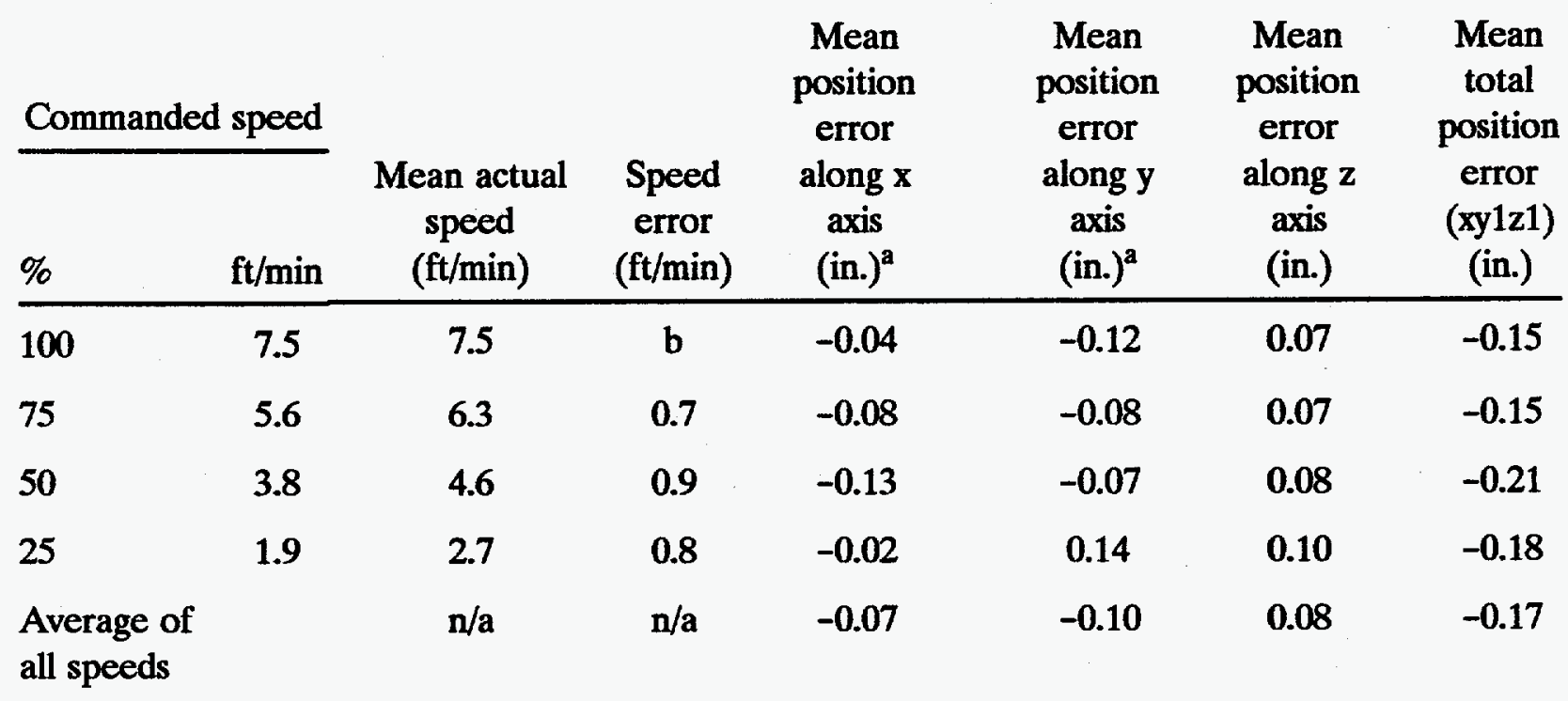

a. No move commanded on this axis.

b. NA. The $100 \%$ speed was used as the basis for the other expected speeds. 
Table 7. Summary of data for moving along the xy1, and $z 1$.

\begin{tabular}{|c|c|c|c|c|c|c|c|}
\hline Commanded & $\mathrm{ft} / \mathrm{min}$ & $\begin{array}{c}\text { Mean actual } \\
\text { speed } \\
\text { (ft/min) }\end{array}$ & $\begin{array}{c}\text { Mean } \\
\text { speed } \\
\text { error } \\
(\mathrm{ft} / \mathrm{min})\end{array}$ & $\begin{array}{l}\text { Mean } \\
\text { position } \\
\text { error } \\
\text { along } x \\
\text { axis } \\
\text { (in.) }\end{array}$ & $\begin{array}{l}\text { Mean } \\
\text { position } \\
\text { error } \\
\text { along y } \\
\text { axis } \\
\text { (in.) }\end{array}$ & $\begin{array}{c}\text { Mean } \\
\text { position } \\
\text { error } \\
\text { along } z \\
\text { axis } \\
\text { (in.) }\end{array}$ & $\begin{array}{c}\text { Mean } \\
\text { total } \\
\text { position } \\
\text { error } \\
\text { (xy1z1) } \\
\text { (in.) }\end{array}$ \\
\hline$\overline{100}$ & 26.6 & 26.6 & a & -0.18 & -0.22 & 0.02 & -0.35 \\
\hline 75 & 20.0 & 21.4 & 1.5 & -0.02 & -0.18 & 0.04 & -0.22 \\
\hline 50 & 13.3 & 16.8 & 2.5 & -0.06 & -0.15 & 0.00 & -0.17 \\
\hline 25 & 6.7 & 8.5 & 1.8 & -0.04 & 0.22 & 0.08 & -0.30 \\
\hline $\begin{array}{l}\text { Average of } \\
\text { all speeds }\end{array}$ & & $\mathrm{n} / \mathrm{a}$ & $\mathrm{n} / \mathrm{a}$ & -0.02 & -0.19 & 0.02 & -0.26 \\
\hline
\end{tabular}

a. NA. The $100 \%$ move was used as the basis for the other expected speeds.

The position after each move was measured using an electronic total station survey instrument (explained below). To find the error, distances were recorded from a local coordinate system for the $\mathrm{x}, \mathrm{y}$, and $\mathrm{z}$ deviations to the nearest thousandth of a foot and then compared to the distances the system was commanded to move. Some uncertainty was introduced into the distance measurements by the placement of the reflectors. The overall uncertainty was estimated to be 0.1 in. by the surveyor/engineer.

A total station is an electronic surveying instrument that combines a theodolite and an electronic distance meter (EDM). A theodolite is used to measure horizontal and vertical angles. An EDM is used to determine the distance between two points by transmitting a signal with an infrared carrier wave that is returned to the EDM by a prism/reflector. The processing unit in the EDM computes the distance based on the phase shift of the returned signal.

During surveying operations, the total station is mounted on a tripod over a known point. A backsight is placed on another known point. The prism/reflector is placed on the unknown point. The total station is used to turn the horizontal angle, shoot the vertical angle, and shoot the slope distance between the two points. The horizontal distance and elevation difference is calculated from the slope distance and the vertical angle. By using (a) coordinates of the known points, (b) horizontal angle, (c) horizontal distance, (d) elevation difference, and (e) the elevation of the known instrument point, the coordinates and elevation of the unknown point can be computed.

Time was recorded to the nearest second using two digital stop watches. The accuracy of the time measurement was estimated by the engineers to be \pm 1 second. Actual speed was determined by dividing the actual distance moved by the time it took to perform the move. 


\subsubsection{Data Validation/Verification}

Data were recorded in tables that were then fixed into the logbooks. Each data sheet was signed by the recorder, a witness, and a reviewer.

No data were dismissed as being invalid or unreasonable.

\subsubsection{Data Analysis}

A statistician calculated the precision and accuracy of the system and evaluated the effects speed and distance moved had on the accuracy and repeatability of positioning.

Speed had little effect on either the precision or accuracy of positioning. There was some evidence that increasing the speed may have increased the accuracy of positioning the $x$ axis; however, the evidence was not conclusive. The CTR system was shown to be very accurate and extremely repeatable in positioning itself.

The test data were combined and statistically analyzed. In this combined data set, each axis was commanded to go to only two positions (one position for the one-direction movement test and one for the 3-D movement test). While two positions did not provide enough data for a complete analysis, a very useful observation can be made from this information. The data show that the accuracies moving only along a single axis are significantly better than the accuracies for the 3-D movement. This difference is caused either by the different distance commanded or by some undetermined effect of 3-D movement. The repeatability (precision) of the movements does not appear to be affected significantly by the distance moved.

Since speed was shown to have very little effect on accuracy and precision, the data from each speed may be combined. Table 8 summarizes the results of the tests by combining these data and providing the overall accuracy and the precision of the delivery system. The accuracy is the average error in positioning; the precision is the standard deviation of the positioning.

The speeds that were tested were commanded through Robline as a percent of full capacity. It should be noted that at this time the speeds have been limited through the Robline software and that the axes movements could actually be performed at higher speeds, if required.

\subsection{Independent Movement and Deployment of Tools}

The test objective for this section of testing was to demonstrate the ability of the equipment to operate in an independent fashion. Independent movement was demonstrated by accomplishing a task involving two operators manipulating the z-masts that were performing two unrelated tasks simultaneously.

The two tasks were (1) simulating characterization at the digface and (2) moving a video camera to independently monitor the characterization effort. The results from these tests are discussed in Section 7.2.1 and 7.2.2, respectively. In addition, the deployment of the vacuum was demonstrated as a tool. Section 7.2.3 addresses the vacuum tests. 
Table 8. Accuracy and precision values from combined data.

\begin{tabular}{ccc}
\hline Axis & $\begin{array}{c}\text { Accuracy } \\
\text { (in.) }\end{array}$ & $\begin{array}{c}\text { Precision } \\
\text { (in.) }\end{array}$ \\
\hline$x$ & -0.24 & 0.20 \\
y1 & -0.15 & 0.06 \\
$\mathrm{z} 1$ & 0.03 & 0.05 \\
xy1z1 & 0.54 & TBD \\
\hline
\end{tabular}

\subsubsection{Deployment of Video Camera}

Figure 2 is a picture of two z-masts performing separate tasks. Z-mast $\mathrm{A}$ is performing the three-point scan plane with a simulated sensor mounted in the manipulator. Z-mast $B$ is providing close video monitoring of the scan by independent movements of the $y$ and $z$ axes of Trolley B and Schilling Manipulator 2.

The planning and execution of this test was successful. For the location and speed selected, planning of the three-point plane took approximately 3 minutes, once the crane had been brought to the first position (point). The plane covered a $10 \mathrm{ft}$ by $10 \mathrm{ft}$ area. The location of the plane was given the operator at the time the test began. Movement of the crane was performed through to the Robline software interface and by use of closed circuit television cameras located around the crane assembly.

During the execution of the scan path by Z-mast A, the axes of Z-mast B were jogged and the Schilling arm (holding a camera) was positioned to provide closeup or full view of the operation, as required for monitoring purposes. The test was run three times. One plane was programmed for parallel scanning of the ground. The other two planes were planned at a skewed angle to the ground. Video footage of the activity was taken.

\subsubsection{Deployment of Digface Characterization}

The test objective for this segment of testing was to demonstrate that digface characterization equipment can be moved in space in a predetermined and controlled manner. This was to be accomplished by performing a scan, using photographic evidence, and documenting that the system can follow a path programmed using the planar path planning algorithms.

7.2.2.1 Data and Data Reduction. Each scan was performed over a $10 \mathrm{ft}$ by $10 \mathrm{ft}$ area with a 1-ft raster offset. The scan execution was set at $100 \%$ of maximum speed. The time it took to program a path (given three points in the $x-y$ plane and execution time) was measured for three separate grids. The exercise was repeated for each grid. Table 9 presents the data for both planning and execution times for characterization activities.

Time was recorded to the nearest second using a digital watch. The accuracy of the time measurement is estimated to be \pm 1 second. 
Table 9. Data from the simulated digface characterization tests.

\begin{tabular}{ccc}
\hline Run & $\begin{array}{c}\text { Planning time } \\
\text { average time } \\
\text { (min:sec) }\end{array}$ & $\begin{array}{c}\text { Planning time } \\
\text { average time } \\
\text { (min:sec) }\end{array}$ \\
\hline 1 & $2: 06$ & $4: 50$ \\
2 & $4: 30$ & $5: 04$ \\
3 & $3: 09$ & $5: 02$ \\
\hline
\end{tabular}

7.2.2.2 Data Validation/Verification. Data were recorded in tables that were then fixed into the logbooks. Each data sheet was signed by the recorder, a witness, and a reviewer. No data were dismissed as being invalid or unreasonable.

7.2.2.3 Data Analysis. The data in Table 9 show the average planning and execution times from each test.

7.2.2.4 Results. The CTR system was very effective in robotically performing a raster movement for the deployment of characterization tools. The time to complete each scan was approximately 5 minutes in each case. Some jerking motion was observed, indicating a need to improve the tuning for some of the joints.

Most of the planning time for each case was used to physically move the mechanism to each of the three points that defined the plane. Once the three points were chosen, it was very easy for the operator to create the path and then begin the scan.

\subsubsection{Vacuum System Tests}

The test objective was to demonstrate the ability of the equipment to deploy a vacuum. This was to be accomplished by documenting that the system could successfully deploy a vacuum by vacuuming 3 gal of sand, gravel, and 1-1/2-in. rock. In addition, the speed of remote and manual vacuuming was to be determined.

7.2.3.1 Data and Data Reduction. The targets that the vacuum had to retrieve were described in Section 3.1.1.2. The vacuum tests were performed four times manually and from the z1-mast. For each test, the time and percent of target vacuumed were recorded. A qualitative evaluation of whether or not the amount of material vacuumed was $90 \%$ or greater was made and a decision on whether that constituted success or failure was recorded. The raw data are presented in Appendix C. Table 10 summarizes the data.

Time was recorded to the nearest second, using two digital watches. The accuracy of the time measurement is estimated to be \pm 1 second.

Data were estimated by the PI for the percentage of volume of waste vacuumed and were recorded in the logbooks for each target. This volume was a visual estimate. The estimated accuracy of the volume measurements is $\pm 5 \%$. 
Table 10. Vacuum test data.

\begin{tabular}{lccc}
\hline Test method & Average time & $\begin{array}{c}\text { Average } \% \text { of targets } \\
\text { vacuumed }\end{array}$ & Success/failure \\
\hline z1-mast & $2 \min 26 \mathrm{sec}$ & $94 \%$ & Success \\
Manual & $17.4 \mathrm{sec}$ & $99 \%$ & Success \\
\hline
\end{tabular}

Success or failure was a qualitative evaluation of the tests. Success was interpreted as $90 \%$ of volume of material vacuumed.

7.2.3.2 Data Validation/Verification. Data were recorded in tables that were then fixed into the logbooks. Each data sheet was signed by the recorder, a witness, and a reviewer. No data were dismissed as being invalid or unreasonable.

7.2.3.3 Data Analysis. The data in Table 10 show the average time for each test. The average time was obtained by adding the total time from the two independent measurements and dividing by two.

7.2.3.4 Results. The manual test was repeated again using a V-shaped attachment to the open end of the hose. It was used to vacuum 3 gal of sand, 3 gal of soil, and $3 \mathrm{gal}$ of 1-1/2-in. rock. There was a significant increase in vacuuming time with the attachment, so only one set of tests was performed. Plunging did not work with this attachment; however, pushing along the ground did give better results than plunging. Because of the differences, the nozzle was cut straight across before the $\mathrm{z} 1$-mast vacuum tests were performed. This also allowed data to be directly comparable because the manual test was initially performed with a straight nozzle.

A t-test was performed to determine if there was a statistically significant difference between the times or efficiency for the two different methods. The manual method was significantly faster than the z1-mast deployment for all target media. The manual method was also significantly better in the percentage vacuumed for all media except gravel. The manual method seemed to retrieve more because the end of the hose could be finessed to enable more target to be retrieved. See Table 11 for details.

An analysis of variance technique was used to further statistically analyze how method and target media affect time and vacuum efficiency. The analysis revealed that the method used (manual versus z1-mast) had a very significant effect on both time and efficiency. Manual performance was better in both cases. Target material was not a significant factor in either time or vacuum efficiency (i.e., it did not really matter much which media was being vacuumed).

During testing, soil was initially targeted during the z1-mast tests. However, because of the recent weather, the dirt was wet and then froze. During vacuuming early in the evening before it froze on the ground, the soil was mud, which caused a buildup of soil at the nozzle entrance. This mud eventually clogged the hose, freezing to the sides of the hose en route to the vacuum hopper. A 2-lb hammer was used to dislocate the frozen mud from the hose. To illustrate how 
Table 11. Results from the vacuum tests.

\begin{tabular}{|c|c|c|c|c|}
\hline \multirow[b]{2}{*}{ Target } & \multicolumn{2}{|c|}{$\begin{array}{c}\text { Time } \\
\text { (seconds) }\end{array}$} & \multicolumn{2}{|c|}{ Percent vacuumed } \\
\hline & Difference $^{a}$ & Significant? & Difference $^{a}$ & Significant? \\
\hline Sand & -135.3 & $\begin{array}{l}\text { Very } \\
(p=0.008)\end{array}$ & 2.5 & $\begin{array}{l}\text { No } \\
(p=0.15)\end{array}$ \\
\hline Gravel & -135.9 & $\begin{array}{l}\text { Very } \\
(p=0.001)\end{array}$ & 5.25 & $\begin{array}{l}\text { Fair } \\
(p=0.07)\end{array}$ \\
\hline $\begin{array}{l}\text { 1-1/2-in. } \\
\text { rock }\end{array}$ & -116.0 & $\begin{array}{l}\text { Very } \\
(p=0.002)\end{array}$ & 6.25 & $\begin{array}{l}\text { Yes } \\
(p=0.04)\end{array}$ \\
\hline
\end{tabular}

a. Difference between mean of manual method minus mean of z1-mast method.

frozen the soil was, a project member threw a piece of frozen soil against the cement and it did not break.

The vacuum tests were successful and provided very meaningful data. The PI added a test for the z1-mast deployment of the nozzle to get a further qualitative feel for how well the robotic deployment of the vacuum would work for larger areas. The nozzle was deployed over piles of sand, gravel, and 1.5-in. rock. Video was taken to document this test. The raster scans were replayed at two different offsets. These tests were successful and the material was retrieved efficiently. A more powerful vacuum could increase the efficiency of retrieval.

One interesting fact that was noted throughout the tests was the need for a "soil-busting" technology. Some of this need arose due to the inclement weather freezing the targets. The project team believed that a "soil-busting" technology would complement the vacuum and increase the amount of target retrieved.

\subsection{Cooperative Movement}

The test objective for this segment of the testing was to demonstrate the ability of the equipment to operate in a cooperative fashion. This was recorded by photographic evidence and documenting that the system achieved cooperative movement by accomplishing three tasks involving cooperative movement.

The first operation involved rigging an oversized object and moving that object. This entailed coordinated movement of the two manipulators and the hoist. The second operation involved tracking an object with a camera. This entailed moving an object with one manipulator and tracking that movement with a camera held by the second manipulator. The third operation involved one manipulator handing an object to the second manipulator. 


\subsubsection{Results}

Rigging of an oversized object involved picking up a 55-gal drum handler with Manipulator 1 and hanging it from the crane hook. A video camera was attached to the wrist of Manipulator 2 to allow for close-up or full-view monitoring of the operation (using the manipulator and/or $\mathrm{y} 2, \mathrm{z} 2$ motions of Trolley $B$ ). The drum handler was then deployed by the hoist ( $x$ axis and Trolley $C y 3$ and $\mathrm{z3}$ crane motions) over a 55-gal drum. Using the hoist hook (z3 motion), the drum handler was lowered onto the end of the drum. The drum handler was skewed relative to the top of the drum so Manipulator 1 was used to adjust it onto the drum. The hoist was then used to pick up the drum and move it.

Video footage was obtained for this tests. Tracking of the object was performed by deploying a camera from the Manipulator 2 as described above.

Figure 3 shows a picture of the two manipulators performing a hand-off task. Video footage of the activity was also taken. Movement of the two Schilling manipulators is available, from the software interface, in several modes. The two modes selected were from the software interface arm teach pendants. The primary modes used were the jog mode and the frame mode. The jog mode allows independent movement and adjustment of individual joints. The frame mode allows for making moves in straight line motion. The arms performed an exchange of a 2-in.-square piece of aluminum tubing. The task was accomplished successfully. It should be noted here that adequate video camera support, with proper attention to location, is critical for this type of work. Orientation of the material and the joints of the arms becomes difficult to synchronize without proper camera support.

\subsection{Failures and System Deficiencies}

The test objective for this portion of the test was to demonstrate the ability of the equipment and processes to operate and to document failures or deficiencies.

The corresponding data quality objective was to document the system failures by logging the number of failures, the nature of the failure, the time required to fix the component/system, what the "fix" entailed, configuration changes, and the cost of the "fix." In addition, any deficiencies that appear in the software, crane, tools, interface, etc., were documented. Routine maintenance were not required during testing.

\subsubsection{Results}

There were several hardware and software failures that occurred during testing. These failures are recorded in detail in the testing logbook and software tracking database. While the number of failures is not unreasonable for prototype equipment, the failures did delay completion of the tests. Following is a discussion of the failures that occurred.

- The Pentium 66-MHz controller processor board failed during testing. This board was selected for the processing power required to calculate trajectories for the crane and the two Schilling manipulators. The processor board was not repaired due to limited time, but was instead replaced with an older 486 processor board. The 486 board 


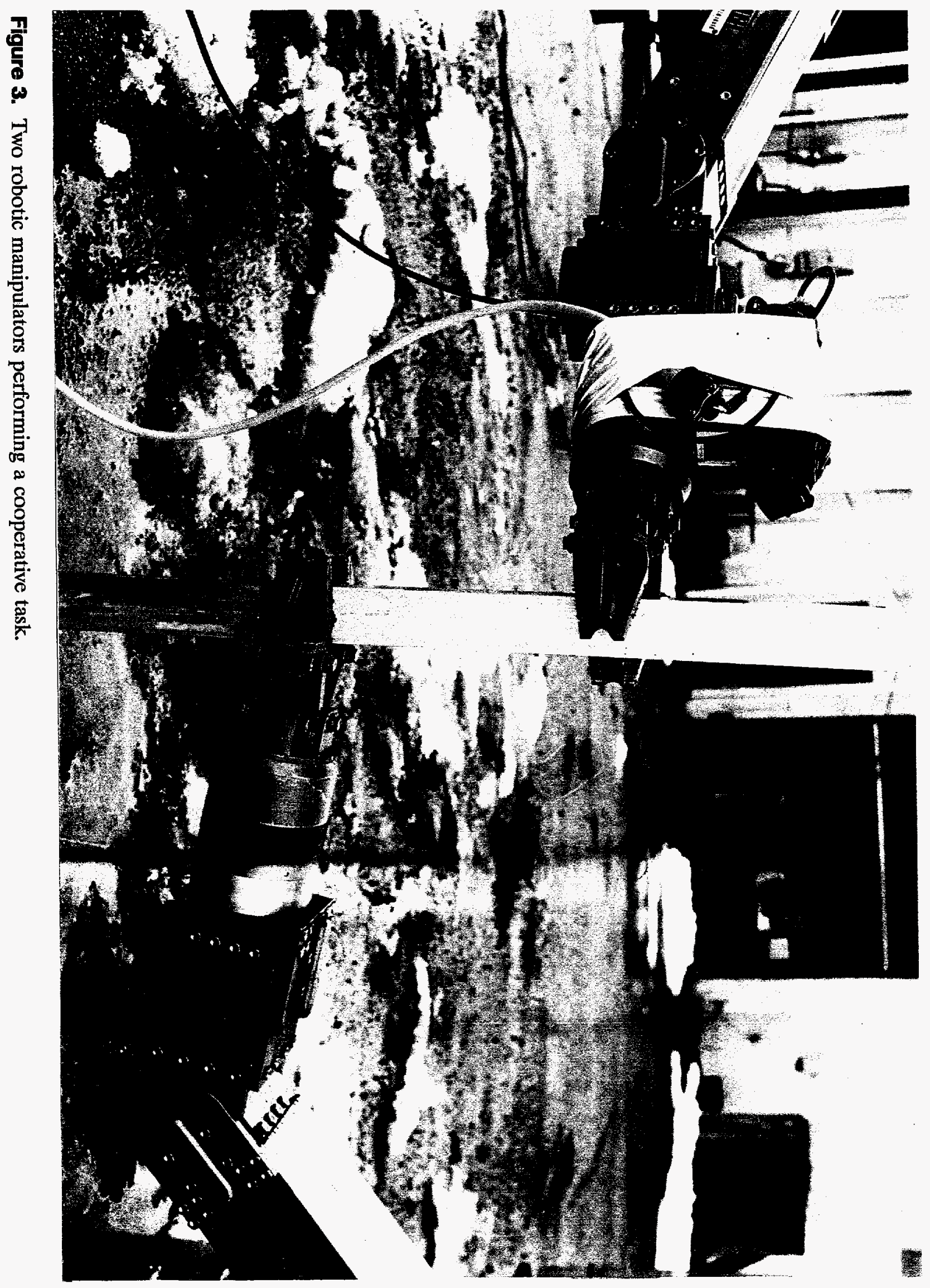


decreased the servo loop update time, causing some jerkiness in the Schilling manipulators, but allowed completion of the tests.

The time needed to fix the controller was approximately 60 minutes, and included removing the Pentium processor board and replacing it with the 486 processor board.

- Several small diameter control wires, brittle from the extremely cold environment, broke during testing.

- Limit switches were broken and replaced during testing.

- The $\mathrm{x}$-axis servo amplifier was found to be defective and required warranty repair at the manufacturer.

- Several software failures occurred (see Section 4.3).

While all of the functions designed for the system have been successfully performed, a few deficiencies in the system were discovered during testing that will be addressed before the FY-95 summer integrated field test. A discussion of these deficiencies follows. Section 11 gives recommendations on how to overcome these deficiencies.

- There is an intermittent failure of the servo control hardware that causes one or more joints to freeze up occasionally. Cycling the power to the servo amplifiers restores operations.

- Occasionally, the Cimetrix software server locks up and must be restarted.

- The use of two forceballs simultaneously is not reliable. At times, the software becomes locked until it is restarted.

- Occasionally, during the homing of the crane through the PMAC cards and sometimes after homing is completed, one or more axes will not move and seems to be due to a servo amp being kicked off. If the power to the servo amplifiers is cycled off and on, then it works again.

- The encoder on the hoist trolley does not give position feedback. During homing, if the hoist amplifier is enabled, the hoist will move to one end of the track and try to push beyond. This is due to the computer looking for increasing or decreasing encoder counts, but always receives that it is in the same place. To avoid this occurrence, the initialization and homing sequences must not enable the hoist mechanism.

- The camera pan and tilt units were not receiving signals from the PMAC controller and, therefore, were inoperable.

- When the z-masts came close enough together to trip the limit switch, one of the trolley's servo amps is killed. Cycling the power for the servo amps seems to clear this problem and allows operations to continue. 
- If there is no tension on the cable that controls the z-mast (because it hit the ground or some obstruction), then the servo amp will keep trying to push it down by letting out more cable. This causes the control cables to unspool and then rewind the cable in an uncontrolled fashion. This can cause serious equipment damage. A similar situation occurs when the servo amplifiers lose power. If the z-mast servo amplifiers lose power, the telescoping booms drop to a rest position where there is no tension on the cable. Again, the cable could have unspooled too much cable. There needs to be a startup mechanism that will restore tension from a rest position before the servo function starts. To get around this problem during testing, the z-masts were moved into a tension position using drvr PMAC card control prior to the oac initialization sequence.

\subsection{Environmental Effects}

The test objective for this portion of the demonstration was to evaluate the system for operation in the test environment. This was to be documented by recording the environmental effects on the system during operation by determining any operational problems due to wind, temperature, and/or precipitation.

\subsubsection{Observations}

Wires attached to the signal connectors of the servo amps were very brittle and could be broken easily when removing the connectors. The wires are small (20 gage) and, when soldered, became very stiff and brittle at the solder joint. With the cold weather, these small wires were easily broken if not handled carefully.

Wind and precipitation did not adversely affect the crane operations. However, the precipitation, followed by freezing temperatures, did prevent the vacuum from being tested with soil. Snow removal also caused some testing delays. In addition, the extreme temperatures outside caused the pneumatic lines to fill with condensation and freeze the water in the lines. This required "defrosting" of the lines.

\subsection{Human-Computer/Nideo Interface}

The objective of this test was to evaluate the system's human-computer and human-video interfaces. This was accomplished by documenting the operators' opinions about the usefulness of the displays and associated software.

\subsubsection{Observations}

The information included in this section on the operator's perceptions of the system is based on operator feedback and observation of the test team.

Adjustability of the console, including table, screens, and chairs would improve the ergonomics of the workstations. A review of the display screens and control mechanisms should be performed and improvements implemented prior to the FY-95 integrated field test. 
Good depth perception is critical for operating equipment such as the manipulators. With the limitations of the 2-D computer screens, it was necessary to provide the operator with a good view of each axis of movement. These views can be best provided by using two cameras-one each on any two of the three axes. However, testing showed that the view of one camera was often blocked by movement of the equipment during operation. In the absence of 3-D vision, a third camera was determined to have been necessary.

To solve this problem during testing, the crane was often operated with the door between the crane and the operator station open.

\subsection{Fulfillment of Data Quality Objectives}

Testing of the system was completed successfully. The data quality objectives for the tests and the fulfillment of the objectives are listed below:

- The delivery system was shown to have no greater than \pm 1 -in. positioning error (with a 95\% confidence level) along any axis at any of the four speeds tested.

- During the tests, the error in the speed of the delivery system was shown to be no greater than $2.1 \mathrm{ft} / \mathrm{min}$ for the $\mathrm{x}$ axis, $0.6 \mathrm{ft} / \mathrm{min}$ for the $\mathrm{y}$ axis, $0.9 \mathrm{ft} / \mathrm{min}$ for the $\mathrm{z}$ axis, and $2.5 \mathrm{ft} / \mathrm{min}$ for a 3-D move. The $\mathrm{y} 2$ and $\mathrm{z} 2$ movements were not demonstrated as planned due to time constraints. However, because the equipment for Trolley $B$ is the same as Trolley $A$, the results are expected to be the same as those for Trolley $A$. Trolley $\mathrm{C}$ ( $\mathrm{y} 3$ and $\mathrm{z} 3$ ) could not be tested because the hoist positioning system was not yet available for testing.

- Successful deployment of a vacuum was documented with sand, gravel, and 1.5-in rock, wet and dry soil as well as small debris. Operating remotely, the vacuum removed 3 gal of dirt/debris in an average of 2 minutes, 26 seconds, while the same task was performed manually in 17.4 seconds.

- System failures documented during the test. Descriptions of the failures and fixes can be found in Section 7.4.

\subsection{Summary}

The CTR system was successfully demonstrated and tested. The CTR system will meet OTD and ER needs for the deployment of various tools within \pm 1 in. Both cooperative and independent movement was accomplished and documented. The tests have resulted in recommendations that can be addressed/implemented to improve the system. 


\section{OUTPUT/PRODUCTS}

\subsection{Data}

Data from these tests are discussed in Section 7. All raw data can be found in the test logbook that can be found in Project File 015683 (currently stored in Jim Jessmore's office) and is copied in the buried waste database.

\subsection{Video/Photographs}

Testing of the CTR system was documented through photographs and video productions of the activities. The purpose of the photographs and videos was to document the tests.

\subsection{Reports}

Testing of the system is documented in Cooperative Telerobotic Retrieval System Test Plan for Fiscal Year 1994.2

\subsection{Residuals}

The main residual of the CTR system was simulated waste that was vacuumed. After testing was completed, the waste was sent to the INEL Landfill and the unused gravel, sand, and rock is being saved for use as fill material for the test site. 


\section{PROBLEMS AND ISSUES FROM TESTING}

\subsection{Weather}

Prior to testing, moisture in the pneumatic lines on the rented vacuum condensed and froze, blocking the hose lines. A heat gun was used to thaw the lines. In addition, the vacuum hopper would not seal properly due to snow on the seal. The area was cleaned and the hose lines were thawed in that area using a heat gun. A person also stood on the edge of the hopper to force the opposite side up to aid in sealing. These efforts were effective and testing was initiated.

\subsection{Technical}

Technical problems, including hardware and software, are discussed in Sections 4.3 and 7.4.

\subsection{Schedule}

Not all of the delivery system tests were performed due to schedule limitations and hardware problems. Based on the results (see Section 7) several recommendations can be made to improve the precision and repeatability of these movements (see Section 11). Once these improvements are made, informal tests will be performed to determine the new achieved performance. This will be performed prior to the summer integrated field test. 


\section{FULL-SCALE IMPLEMENTATION}

\subsection{Overview}

The CTR system is a highly reliable system that would be useful for both characterization and retrieval of zones of environmental concern and support to larger excavation equipment for a full pit retrieval. Because the system is remotely operated, it provides protection for personnel. Considerations for full-scale implementation are discussed in this chapter. The chapter is divided into implementability, effectiveness, and cost to aid ER in comparing this technology to others during the remedial investigation. The areas addressed correspond directly to the CERCLA criteria.

\subsection{Implementability}

Implementability includes the following:

- Ability to construct and operate the technology

- Reliability of the technology

- $\quad$ Ease of undertaking additional remedial actions, if necessary

- Ability to monitor effectiveness of remedy

- Ability to obtain approvals from other agencies

- Coordination with other agencies

- Availability of offsite treatment, storage, and disposal services and capacity

- Availability of necessary equipment and specialists

- Availability of prospective technologies.

Each of these is briefly discussed below.

\subsubsection{Ability to Construct and Operate the Technology}

Section 7 discusses the operator's ability to operate the equipment. For the purposes of comparing this technology to others, the following should be noted. The remote gantry crane was designed and fabricated by a standard crane manufacturer. The manufacturer was selected by competitive bid and performed the work according to a functional specification that was provided by EG\&G Idaho, Inc. The contract included all mechanical and power design, procurement, fabrication, and assembly efforts. Controls and sensors were provided by EG\&G Idaho. Lead time for the crane, from award of contract, was 22 weeks. A conservative lead time uncertainty of \pm 3 weeks for crane delivery is assumed. Assembly and integration of the control system and 
sensors at the NBA facility took 5 weeks (excluding 5-week schedule delay due to administrative concerns regarding hoisting and rigging rules as applied to assembly at a DOE leased facility) to assemble the mechanical elements of the crane. An uncertainty of \pm 2 weeks was applied to final system assembly. System testing occupied approximately 3 weeks of time. An uncertainty of \pm 2 weeks was applied to testing of the system. Subsequent modifications to the system, based on testing, would further change the uncertainties associated with redesign, new design, and implementation of these into the final product. Factoring in all of the above, a similar system, with modifications included, should be available in under 20 weeks, with an estimated uncertainty of \pm 2 weeks.

Power for the crane and all its subsystems may be provided by remote generators and/or facility line power. Currently, power is provided to the crane via facility power. Power to the vacuum system is by a remote diesel generator.

Weather could affect the implementability of the current system. Extremely cold temperatures affected wires by causing them to become brittle. Precipitation followed by freezing temperatures froze soil targets so hard that vacuuming them was impossible. In addition, the cold caused condensation in the pneumatic line of the vacuum to freeze, causing a delay to heat up the line and flush the fluid out of the line.

\subsubsection{Reliability of CTR System}

Reliability as discussed here focuses on the likelihood that technical problems associated with implementation will lead to schedule delays. During the tests conducted, no failures occurred, making this area an unknown. However, several technical factors should be addressed during set up of the equipment to ensure no schedule delays. These factors include ensuring proper power, routing wiring so that no interference from other electrical cords occurs, ensuring no radio frequency interference for various tools being deployed off of the crane, ensuring wires for telerobotic gantry crane controls are routed or replaced with radio frequency links, and planning paths so that the wiring is not in the path of the crane or other remote equipment such as a remote excavator and/or conveyance system.

Scheduled maintenance includes following the maintenance schedule associated with the maintenance manual provided by the crane manufacturer. This includes the periodic checking of bearings, mounting bolts, transfer case oil level, and hoist cables and guides. Manipulator maintenance includes following the manipulator arm manufacturers recommended maintenance schedule. This includes checking of hydraulic oil level in the pump, replacement of suction and discharge filters on the hydraulic power unit, and periodic tightening of fittings and fasteners on the arms.

Daily maintenance requires approximately one-half hour. This primarily covers visual inspection of the system to detect problems. Repair or replacement of items on the equipment was logged for historical purposes. 


\subsubsection{Ease of Undertaking Additional Remedial Actions, If Necessary}

The technology discussed in this report allows the waste to be retrieved from the digface and/or zone of environmental concern. It does not in any way affect the future treatment of the waste. The only technology that may be precluded by use of this system is in situ treatment. Note that if other technologies are used in conjunction with the gantry crane (such as spraying the digface with fixants or surfactants to further limit airborne dust), these additional technologies may affect the characterization or treatment technologies selected.

Removal of the buried waste using a vacuum is a preliminary sorting activity. This will aid in subsequent repackaging and treatment activities.

\subsubsection{Ability to Monitor Effectiveness of Remedy}

The effectiveness of the remedy can be monitored several ways. First, the remote gantry crane must remove the waste. The effectiveness of this can be measured several ways. First of all, the video images can show operators where they have dug and allow them to see if waste is visible. The second method would be to use characterization technologies (such as digface characterization) to determine if waste remains. The gantry crane can be adapted to deploy contamination control fixants and surfactants that minimize potential airborne contamination spread. This can be monitored by use of air monitors such as constant air monitor (CAM) radiation monitors for a hot retrieval.

\subsubsection{Ability to Obtain Approvals from Other Agencies}

The permits and approvals required from agencies other than the DOE for full-scale operation would depend on the site to be remediated. There would not be any special permits required for the CTR system. The NEPA documentation should address petroleum products storage (hydraulic fluid) and noise levels.

\subsubsection{Coordination with Other Agencies}

Coordination with other agencies would depend on the site to be remediated. For example, at the INEL, ER would need to coordinate with DOE, the Idaho Department of Health and Welfare, and U.S. Environmental Protection Agency Region 10. Other sites would need to coordinate with agencies listed in their interagency agreements.

\subsubsection{Availability of Offsite Treatment, Storage, and Disposal Services and Capacity}

The CTR system would not preclude the use of any available offsite treatments, storage facilities, or disposal services. The waste being retrieved for a specific site would dictate which of these services could be used. Once that was determined, the availability of those services could be addressed. 


\subsubsection{Availability of Necessary Equipment and Specialists}

The availability of the necessary equipment is discussed above, under "Ability to Construct and Operate the Technology." For full-scale implementation in a radioactive environment, the operators should have (1) training for responding to incidents and emergencies based on the configuration of the buried waste, (2) 40 hours of experience on the remote equipment in a nonhazardous, nonradioactive environment, and (3) 40 hours of OSHA site-specific training. The time to train the operators is minimal. Certified safety professionals (health physicists and industrial hygienists) would be required to respond and to direct personnel.

\subsubsection{Avallability of Prospective Technologies}

The prototype system was tested in December 1994. This equipment is currently being modified as discussed in this report. A full-scale field test of the upgraded equipment is currently scheduled for the summer of 1995.

\subsection{Effectiveness}

Effectiveness entails (a) overall protection of human health and the environment, (b) compliance with applicable or relevant and appropriate requirements (ARARs), (c) long-term effectiveness and permanence, (d) reduction of toxicity, mobility, and volume through treatment, and (e) short-term effectiveness. Compliance with ARARs is site specific and is therefore omitted from this discussion. The other areas of effectiveness are discussed below.

- Overall protection of human health and the environment

- How the technology provides human health and environmental protection

- Long-term effectiveness

- Magnitude of residual risk

- Adequacy and reliability of controls

- Reduction of toxicity, mobility, and volume

- Treatment process used and materials treated

- Amount of hazardous materials destroyed or treated

- Degree of expected reductions in toxicity, mobility, and volume

- Degree to which treatment is irreversible

- Type and quantity of residuals remaining after treatment

- $\quad$ Short-term effectiveness 
- Protection of community during remedial actions

- Protection of workers during remedial actions

- Environmental impacts

- Time until remedial action objectives are achieved.

Each of these is briefly discussed below.

\subsubsection{Overall Protection of Human Health and the Environment}

The system is an improvement over conventional excavators because the equipment is remote, thereby reducing the risk due to exposure to workers. Therefore, the system protects both human health and the environment.

\subsubsection{Long-Term Effectiveness}

10.3.2.1 Magnitude of Residual Risk. Magnitude of residual risk refers to the risk remaining from untreated waste or treatment residuals at the conclusion of remedial activities. The risk would be a function of the waste being retrieved, the levels of contamination remaining, the effected exposure pathways, and the projected land use, and cannot be addressed at this time. However, the retrieval system would affect whether or not all the waste was removed from the site. Because of this, it is recommended that a sizing method be available on site to reduce the waste into a size that the system can handle.

10.3.2.2 Adequacy and Reliability of Controls. The adequacy and reliability of controls refers to the management of treatment residuals or untreated wastes that remain at the site. Again, the treatment residuals would depend on the specific waste and the treatment method chosen. However, the retrieval system would affect whether or not all the waste was removed from the site. Because of this, it is recommended that a sizing method be available onsite to reduce the waste into a size that the remote crane system can handle. Alternatives to the sizing method would be to assess in situ treatment, containment systems, and institutional controls to ensure that any exposure to human and environmental receptors is within protective levels.

\subsubsection{Reduction of Toxicity, Mobility, and Volume}

10.3.3.1 Treatment Process Used and Materials Treated. The CTR system does not treat the waste, so this section is not applicable. However, it is important to note the types of wastes the system can retrieve and any limitations. The gantry crane system was very efficient in handling diverse waste forms. The system is limited by the weight that it can handle. The maximum weight that the end-effector can pick up at full extension is $240 \mathrm{lb}$. The maximum weight the $\mathrm{z}$-mast can hold is $2,000 \mathrm{lb}$ and the maximum weight the crane hook can have is $10,000 \mathrm{lb}$. The system should be able to retrieve any hazardous or radioactive materials including sludges, slurries, dirts, debris, etc. Size of objects may also be limited to the size that the CTR system tools can handle. In addition, objects must be within the working envelope of the crane. 
10.3.3.2 Amount of Hazardous Materials Destroyed or Treated. The CTR system does not treat the waste, so this section is not applicable to this technology.

10.3.3.3 Degree of Expected Reductions in Toxicity, Mobility, and Volume. The system does not change the waste toxicity or volume. The CTR system does address the mobility of the waste in that it retrieves the waste from the contaminated area for subsequent storage or treatment. However, the small fraction of waste that becomes airborne may have an increased mobility.

10.3.3.4 Degree to Which Treatment Is Irreversible. The remote system does not treat the waste so this section is not applicable. However, it is important to note that the retrieval actions are totally reversible in that the waste could be put back into the pit if this were desirable.

10.3.3.5 Type and Quantity of Residuals Remaining After Treatment. The CTR system does not treat the waste, so this section is not applicable. However, it is important to note the secondary wastes that would be produced as a result of using the system. The types of wastes include, but are not limited to:

- Hydraulic fluid

- $\quad$ Bearing grease

- Residuals from decontamination process

- $\quad$ Personal protective equipment

- Rags.

Note that the volume of the contaminated material is dependent on the number of hours that the equipment is operated.

\subsubsection{Short-Term Effectiveness}

10.3.4.1 Protection of Community During Remedial Actions. This aspect of short-term effectiveness addresses any risk that results from implementation of the technology. Note such risks are specific to hazards associated with the site (i.e., off-gassing, explosion, spontaneous combustion). For this system, the following risks should be considered: airborne dust generated during retrieval at the digface, during transfer to a conveyance system or box, and risks associated with the transportation of the wastes.

10.3.4.2 Protection of Workers During Remedial Actions. The technology is remote and, therefore, protects the workers from the hazards and radiation at the digface. The only time that workers may be required to enter the area is for scheduled and unscheduled maintenance or for unplanned spill cleanup.

10.3.4.3 Environmental Impacts. Environmental impacts refer to the adverse impacts that occur during the construction and implementation of a technology. These impacts would be 
dependent upon the specific site being remediated and the administrative controls over the area. The remote system would not adversely effect the environment, but would generate noise.

Construction noise results from equipment required to install concrete footings for the crane rails. The equipment used is standard construction equipment such as a backhoe, cement truck, concrete vibrator, power hand saws, and drills. Assembly of the crane results in noises generated by hoisting equipment, trucks, etc. Operationally, noise is generated by a hydraulic power unit and the vacuum system. Both of these systems are commercially available and do not exceed maximum noise level requirements for use without hearing protection. These hazards are considered minimal and standard in a construction environment and should be addressed in NEPA documentation.

10.3.4.4 Time Until Remedial Action Objectives Are Achieved. The results in Section 7 indicate that with the current system, approximately $22 \mathrm{yd}^{3} /$ day of waste can be retrieved using the system. Specific tests on use of another vacuum sundering system, grapple, drum handler, box handler, and slings will be performed during the FY-95 integrated field test.

\subsection{Costs}

Costs includes the following:

- Capital costs

- $\quad$ Operating and maintenance costs.

The system discussed above is remote and is estimated to have a useful life of 20 years for the crane. The manipulator systems (including hydraulic power unit), depending on the type of service, will have a life of approximately 5 years. A vacuum system of the type required here will normally exhibit a life of $\mathbf{1 0}$ years. Therefore, the system could protect personnel from radiation for that period of time (maintenance time is not considered in operating hours). These systems replace one to three operators that would be required to conduct similar operations onsite.

The DOE has established dose limits that have been even more limited by the DOE contractors to achieve those goals. The current administrative control during routine conditions is 1-5 rem/yr and it is recommended that workers not be exposed above a maximum of 300 mrem/wk. It is impossible to draw concise conclusions regarding the amount of exposure reduction without knowing the exact site conditions and other unpredictable conditions. However, an example would be that operators are exposed to $100 \mathrm{mrem} / 8 \mathrm{hr}$ shift. Assuming this condition and assuming one to three operators at a time, the remote crane equipment over its useful life would reduce exposure by 500-1,500 rem.

The following sections provide a discussion regarding the costs for these remote systems. The total capital costs for a production version of the system is estimated to be approximately $\$ 895 \mathrm{~K}$. The cost efficiency of these systems is between $\$ 600$ /person-rem and $\$ 1,790$ /person-rem based on the assumptions discussed above. 
The INEL Robotics target is to spend less than $\$ 4,795 /$ person-rem for remotizing a technology. This is based on an exposure limit of $1,500 \mathrm{mrem}$, contamination levels greater than $20,000 \mathrm{dpm}$, general body field greater than $500 \mathrm{mrem} / \mathrm{hr}$, two entries, a pre-job briefing of $3 \mathrm{man}$ hours (one worker at $\$ 38 / \mathrm{hr}$, one Radiological Control Technician at $\$ 38 / \mathrm{hr}$, and one supervisor at $\$ 60 / \mathrm{hr}$ ), personal protective equipment and clothing collection for the worker, and $4 \mathrm{ft}^{3}$ of waste. This cost is adjusted lower because the worker can be used to work in other areas, the training cost per man-rem is reduced. The CTR system costs of $\$ 600 /$ person-rem to $\$ 1,790$ /person-rem compares very favorably to the target expense of less than $\$ 4,795 /$ person-rem. Therefore, based on these assumptions this technology is a cost-effective method of reducing personnel radiation exposure.

\subsubsection{Capital Costs}

Capital costs consist of direct (construction) and indirect (nonconstruction and overhead) costs. Direct costs include construction costs (materials, labor, and equipment to prepare for use), equipment costs, land and site development costs, buildings and services costs, relocation expenses, and disposal costs. Indirect capital costs include engineering expenses, license or permit costs, startup and shakedown costs, and contingency allowances. Table 12 depicts the estimated capital costs associated with the CTR system. Because of unknowns and only rough order of magnitude estimates, only the equipment costs are included.

The actual cost of the equipment entails the gantry crane, vacuum system, control station, and supporting equipment such as the hydraulic pump, wiring, cable routers, etc. (Note that labor and materials have not been estimated.) Land and site development costs may be required for footings for the operation of the gantry crane system. The buildings and services refer to costs that are additional costs that may be required as a result of using the technology. This is difficult to estimate because the site conditions are unknown and so are the other technologies that are required. The building, if required, would need to be big enough to house the equipment and allow effectively maneuvering within it. Relocation expenses refer to costs for temporary or

Table 12. Partial list of direct capital equipment costs.

\begin{tabular}{ll}
\hline Equipment & $\begin{array}{l}\text { Cost } \\
(\$ \mathrm{~K})\end{array}$ \\
\hline Gantry crane & 350 \\
Manipulators (2) & 250 \\
$\quad$ Schilling Titan 2 & \\
Vacuum system & 10 (rental or 40 to buy) \\
$\quad$ Rental \$1K/week & \\
Control system & 180 \\
$\quad$ Graphics, fiber optics, etc. & \\
Video equipment & 25 \\
Supporting equipment & 50 \\
\hline
\end{tabular}


permanent accommodations for affected nearby residents. This cost would depend on the site that was being remediated and would not be affected by the equipment itself. Disposal costs include the costs for transporting and disposing of the waste material. This cost is also sitespecific and therefore cannot be estimated. However, the only added waste as a result of the system that would need to be treated/disposed would be the waste generated from decontaminating the equipment and from maintenance of the equipment (used fluid, oil, broken parts, etc.).

Indirect capital costs for engineering expenses would include demonstration support, program management, performance of the tests, quality assurance, safety, and shipping expenses. Licenses and permits would be obtained based on the particular site being remediated. These costs would not be affected by the remote system. Startup and shakedown costs are the costs to ensure the remote system is operational and functional. Contingency refers to money to cover costs resulting from unforeseen circumstances such as adverse weather, waste variability not anticipated, equipment repair, explosion, fire, etc.

\subsubsection{Operating and Maintenance Costs}

Operating and maintenance costs are incurred after construction costs and are necessary to ensure the continued effectiveness of a remedial action. The following are considered operating and maintenance costs: operating labor costs; maintenance materials and labor costs; auxiliary materials and energy; disposal of residues; purchased services; administrative costs; insurance, taxes, and licensing costs; maintenance reserve and contingency funds, rehabilitation costs, and costs of periodic site reviews.

The CTR system can be operated by one primary operator and one secondary operator. Two operators allow for both independent and cooperative tasks. A third operator could be used for manipulating the hook and keeping apprised of maintenance needs, etc. At this time, it does not appear that a third operator would be required.

Retrieval rates will depend on what is being retrieved. A representative rate will be obtained during the FY-95 summer integrated field test and will subsequently be reported. 


\section{CONCLUSIONS AND RECOMMENDATIONS}

\subsection{Conclusions}

The primary purpose of the CTR system is to remove operators from the inherent dangers of characterizing and retrieving objects in a hazardous or radioactive environment. The prototype CTR system was successfully tested in early FY-95. The lessons learned from the test have provided a solid basis to improve the system to support the FY-95 integrated field test and future remediation activities at the INEL and other sites.

The CTR system will increase the safety of workers by removing them from the site while providing a delivery platform for various tools. The CTR system provides the basis for investigations into remote retrieval of buried waste sites using virtually any type of tool desired. The system provides for unobstructed accessibility to the subject area. Cooperation of several devices is possible. Because of the control system, specific positions and locations are easily acquired, data stored, and reacquired, thus allowing for the accurate deployment of a number of tools at a singular location.

\subsection{Recommendations}

The following recommendations are made:

- The camera systems affected the operators by not providing depth perception. The images from the cameras were seen in the control console as monocular flat screen displays. A better camera system to provide the operator with more visual acuity and help the operator get a sense of depth would be very useful.

- Remotely controlling the zoom and iris functions of the cameras mounted on and around the gantry system are necessary. Funding for these investigations and modifications have been provided for in FY-95 and will be demonstrated at the field test.

- Further development of a human-engineered control console to optimize controls and displays would increase the productivity of the operators and reduce the chance of error.

- The development of a universal tool changer that would allow remote changeout between multiple tools is needed. This task will be accomplished prior to the FY-95 integrated field test.

- A device that can move the Schilling manipulators to allow passage to the crane extension is needed. This project is funded to design and build this device prior to the FY-95 integrated field test.

- For use in a remediation task, the hydraulic system should be reviewed to see if changeover to a nonhazardous and nonflammable fluid would be possible and would not 
be cost prohibitive. This is being considered for the FY-95 integrated field test, depending on the cost impact and added wear on system parts/seals.

- Another improvement that may enhance the future cost effectiveness of remediating multiple sites would be to modify the crane system to be able to mobilize the crane on wheels. This would allow the crane to be moved from area to area without disassembling and reassembling the crane each time. Other mobilization options should also be investigated. No funding has been allocated to perform this task.

- Cable and hose management on the gantry crane should be arranged such that appropriate break points exist in the system to allow dismantlement without having to remove all of the hoses or cables out of the cable trays. This is especially important for the hydraulic system to prevent the need to drain the system with each setup and teardown.

- There needs to be a startup mechanism that will restore tension from a z-mast rest position before the servo function starts. This will prohibit cable from incorrectly spooling on the z-mast cable drums.

- Operation of the crane system and manipulators is possible through both a software $\mathrm{x}$-windows interface and a hardware device called a "force ball." Further development of the force ball interface is necessary, as this is not an intuitive device for operating the system. It is commonly used in other government facilities and locations, but requires practice to become a useful tool. Other interface devices should be investigated in order to enhance the flexibility and use of this equipment. 


\section{REFERENCES}

1. Technology Needs Crosswalk Report, First Edition, DOE/LD/12584-117, GJPO-109, January 1993.

2. R. A. Hyde and K. M. Croft, Cooperative Telerobotic Retrieval System Test Plan for Fiscal Year 1994, INEL-94/0035, October 1994.

3. S. Walker, Environmental, Safety, Health, and Quality Plan for the Buried Waste Integrated Demonstration Program, EGG-WTD-11216, May 1994.

4. H. G. Vega, S. B. French, and D. L. Ricks, Training Requirements and Responsibilities for the Buried Waste Integrated Demonstration at the Radioactive Waste Management Complex, EGG-WTD-10400, September 1992. 


\section{Appendix A}

\section{Modified Test Procedures}





\section{PROCEDURES TO BE FOLLOWED FOR ALL TEST SEQUENCES}

There are several measurements that should be recorded in the logbook throughout the following test sequences. These include the environmental conditions, any deficiencies or difficulties encountered during testing, any system failures, and any maintenance performed. Each of these measurements, whether quantitative or qualitative, is discussed below. The test sequences follow this general discussion.

\section{A. Environmental Conditions}

The environmental effects on the system will be monitored. The weather conditions in Idaho Falls will be measured during testing, and any effects of the environment on the system will be noted in the project logbooks for later analysis. Wind speed, temperature, and amount of rainfall/snowfall will be recorded by the National Oceanic and Atmospheric Administration (NOAA). In addition, any noticeable effects of other environmental conditions will be recorded in the logbooks. Copies of charts showing the environmental conditions will be included in the Technology Evaluation Report.

\section{B. Deficiencies or Difficulties}

Any deficiencies that appear in the software, crane, tools, interface, etc., will be recorded in logbooks and identified in the Technology Evaluation Report.

\section{Failures}

All failures will be recorded in the logbooks. Measurement parameters will include documenting the number of failures, the nature of the failure, the time required to fix the component/system, what the "fix" entailed, configuration changes, and the cost of the "fix."

\section{Maintenance Activities}

Routine maintenance operations, if required, will also be recorded in the logbooks. The type of maintenance, what materials were used, and the time it took to perform the maintenance will specifically be called out in the logbooks.

\section{E. Camera Tests}

This test will involve documenting the overall time that operators viewed each video image. This information will allow the team to determine which camera views the operators used the most. This information should be useful in planning camera placement and operator views for the FY-95 integrated demonstration. In addition, any operator comments regarding the controls or displays shall be recorded in the logbook. 


\section{DELIVERY SYSTEM}

\section{A. General}

The accuracy and repeatability of the $\mathrm{x}, \mathrm{yl}, \mathrm{zl}$, and $\mathrm{xy} 1 \mathrm{z} 1$ axes will be determined at four speeds $(100 \%, 75 \%, 50 \%$, and $25 \%$ of capacity). This test will be performed by moving each axis to two separate locations in space and measuring the inaccuracy of the axis being tested from a local coordinate system using a total station to survey the locations. Each axis will be tested independently to determine the inaccuracies of just that axis. In addition, interactions between the axes will be tested by moving the crane to two locations in space. Table A-1 shows the speeds that will be tested for each axis.

The commanded versus actual speed will also be determined during these tests. Table A1 above shows the commanded speeds. Stopwatches will be used to determine the actual speeds the axes move. In order to more effectively determine the speeds, the points in space that each axis must target will be at least $x=20, y=20$, and $z=3 \mathrm{ft}$ from the start position. Because the distance that each axis moves may affect the precision, accuracy, and repeatability of that movement, the tests will be performed for the locations shown in Table A-2. Initiation of the movements will be from the home position. Each test will be repeated 5 times.

Table A-1. Speeds that were tested.

\begin{tabular}{||l|l|l|l|l||}
\hline \multirow{2}{*}{ Axis } & \multicolumn{4}{|c|}{$\begin{array}{c}\text { Percent of Capacity } \\
\text { (ft/min) }\end{array}$} \\
\cline { 2 - 5 } & $\mathbf{1 0 0 \%}$ & $\mathbf{7 5 \%}$ & $\mathbf{5 0 \%}$ & $\mathbf{2 5 \%}$ \\
\hline $\mathrm{x}$ & 30.1 & 22.6 & 15.1 & 7.5 \\
\hline $\mathrm{y} 1$ & 23.1 & 17.3 & 11.6 & 5.8 \\
\hline $\mathrm{z} 1$ & 7.5 & 5.6 & 3.8 & 1.9 \\
\hline
\end{tabular}

Table A-2. Target Locations.

\begin{tabular}{|l|l|}
\hline \multicolumn{1}{|c|}{ Axis } & \multicolumn{1}{c|}{$\begin{array}{c}\text { Location } \\
\text { (inches from home) }\end{array}$} \\
\hline $\mathrm{x}$ & $300,0,0$ \\
\hline $\mathrm{y} 1$ & $0,300,0$ \\
\hline $\mathrm{z} 1$ & $0,0,36$ \\
\hline $\mathrm{xy} 1 \mathrm{z} 1$ & $100,100,36$ \\
\hline
\end{tabular}




\section{B. Materials and Equipment}

The following materials and equipment will be required to perform the tests outlined above and discussed in detail below.

- One lab notebook

- Two pens

- Gantry crane system and controls/displays

- Video camera for photographic evidence of tests

- Videotapes

- Two stopwatches

- A total station for surveying.

\section{Precautions}

No personnel should be in the immediate area of the gantry crane while it is in operation. The immediate area shall be defined by the PI and roped off accordingly. If the gantry crane needs to be repaired during the tests, precautions for lock out and tag out shall be taken.

\section{Procedure}

The following is a step-by-step procedure for completing the delivery system tests. The steps should be followed chronologically starting with Step 1. Data shall be recorded on the sheets given in A-1.5, "Data Collection Sheets," and taped into the logbook.

Step 1. Area readiness check.

Step 1.1 Ensure that the materials are within the working area. The materials will include a total station and a video camera.

Step 1.2 Remove all obstructions and unnecessary materials from the area.

Step 1.3 Ensure that the immediate area is roped off.

Step 2. Gantry readiness check.

Step 2.1 Unhook the crane restraint.

Step 2.2 Verify manipulators are stowed. 
Step 3. Start system.

Step 3.1 Power up the system.

Step 3.2 Start the hydraulics.

Step 3.3 Initialize the software.

Step 3.4 Home the crane.

Step 4. Start videotaping of the tests.

Step 5. Test the $\mathrm{x}$ axis movement.

Step 5.1 Set the speed to $100 \%$ capacity for the $\mathrm{x}$ axis.

Step 5.2 Move the crane to location A. Time this move. Record the time in the logbook.

Step 5.3 Measure the accuracy of the move using the total station. Record these results in the logbook.

Step 5.4 Home the crane.

Step 5.5 Measure the accuracy of the home move using the total station. Record these results in the logbook.

Step 5.6 Repeat Steps 5.2-5.7 with a crane speed at 50\% capacity.

Step 5.7 Repeat Steps 5.2-5.7 with a crane speed at 75\% capacity.

Step 5.8 Repeat Steps 5.2-5.7 with a crane speed at 25\% capacity.

Step 5.9 Repeat Steps 5.1-5.10 four more times.

Step 6. Test the y1 axis movements.

Step 6.1 Set the speed to $100 \%$ capacity for the $y 1$ axis.

Step 6.2 Move the crane to location A. Time this move. Record the time in the logbook.

Step 6.3 Measure the accuracy of the move using the total station. Record these results in the logbook.

Step 6.4 Home the crane. 
Step 6.5 Measure the accuracy of the home move using the total station. Record these results in the logbook.

Step 6.6 Repeat Steps 6.2-6.7 with a crane speed at $50 \%$ capacity.

Step 6.7 Repeat Steps 6.2-6.7 with a crane speed at $75 \%$ capacity.

Step 6.8 Repeat Steps 6.2-6.7 with a crane speed at $25 \%$ capacity.

Step 6.9 Repeat Steps 6.1-6.8 four more times.

Step 7. Test the $\mathrm{z} 1$ axis movements.

Step 7.1 Set the speed to $100 \%$ capacity for the $\mathrm{z} 1$ axis.

Step 7.2 Move the crane to location A. Time this move. Record the time in the logbook.

Step 7.3 Measure the accuracy of the move using the total station. Record these results in the logbook.

Step 7.4 Home the crane.

Step 7.5 Measure the accuracy of the home move using the total station. Record these results in the logbook.

Step 7.6 Repeat Steps 7.2-7.7 with a crane speed at 50\% capacity.

Step 7.7 Repeat Steps 7.2-7.7 with a crane speed at $75 \%$ capacity.

Step 7.8 Repeat Steps $7.2-7.7$ with a crane speed at $25 \%$ capacity.

Step 7.9 Repeat Steps 7.1-7.8 four more times.

Step 8. Test movement in the xy1z1 axes.

Step 8.1 Set the speed to $100 \%$ capacity for the $x y 1 z 1$ axes.

Step 8.2 Move the crane to location A. Time this move. Record the time in the logbook.

Step 8.3 Measure the accuracy of the move using the total station. Record the results.

Step 8.4 Home the crane.

Step 8.5 Measure the accuracy of the home position using the total station. 
Record the results.

Step 8.6 Repeat steps $8.2-8.5$ with a crane speed at $50 \%$ capacity.

Step 8.7 Repeat steps $8.2-8.5$ with a crane speed at $75 \%$ capacity.

Step 8.8 Repeat steps 8.2-8.5 with a crane speed at $25 \%$ capacity.

Step 8.9 Repeat steps 8.1-8.8 two more times.

Step 9. Stop videotaping.

Step 10. System shut down.

Step 10.1 Home the crane.

Step 10.2 Stow the manipulators.

Step 10.3 Power down the crane and hydraulics.

E. Data Collection Sheets

Data shall be recorded on the following sheets and taped into the testing logbook. 
X Axis - Run

\begin{tabular}{||l|l|l|l|l|l||}
\hline \multicolumn{1}{|c|}{ Commanded } & $\begin{array}{c}\text { Time 1 } \\
\text { Time 2 } \\
\text { Average time }\end{array}$ & $\begin{array}{c}\mathrm{x} \text { distance } \\
\text { (in.) }\end{array}$ & $\begin{array}{c}\mathrm{y} \text { distance } \\
\text { (in.) }\end{array}$ & $\begin{array}{c}\mathrm{z} \text { distance } \\
\text { (in.) }\end{array}$ & Comments \\
\hline $\begin{array}{l}100 \% \\
\text { Location A }\end{array}$ & & & & & \\
\hline $\begin{array}{l}50 \% \\
\text { Location A }\end{array}$ & & & & & \\
\hline $\begin{array}{l}75 \% \\
\text { Location A }\end{array}$ & & & & & \\
\hline $\begin{array}{l}25 \% \\
\text { Location A }\end{array}$ & & & & & \\
\hline
\end{tabular}

Date

Recorded by:

Witnessed by:

Reviewed by: 
Y1 Axis - Run

\begin{tabular}{||l|l|l|l|l|l||}
\hline \multicolumn{1}{|c|}{ Commanded } & $\begin{array}{c}\text { Time 1 } \\
\text { Time 2 } \\
\text { Average time }\end{array}$ & $\begin{array}{c}\mathrm{x} \text { distance } \\
\text { (in.) }\end{array}$ & $\begin{array}{c}\mathrm{y} \text { distance } \\
\text { (in.) }\end{array}$ & $\begin{array}{c}\mathrm{z} \text { distance } \\
\text { (in.) }\end{array}$ & Comments \\
\hline $\begin{array}{l}100 \% \\
\text { Location A }\end{array}$ & & & & & \\
\hline $\begin{array}{l}50 \% \\
\text { Location A }\end{array}$ & & & & & \\
\hline $\begin{array}{l}75 \% \\
\text { Location A }\end{array}$ & & & & & \\
\hline $\begin{array}{l}25 \% \\
\text { Location A }\end{array}$ & & & & & \\
\hline
\end{tabular}

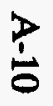

Signature

Date

Recorded by:

Witnessed by:

Reviewed by: 


\begin{tabular}{|c|c|c|c|c|c|}
\hline \multicolumn{4}{|c|}{ Z1 Axis - Run } & \multirow[b]{2}{*}{$\begin{array}{l}\mathrm{z} \text { distance } \\
\text { (in.) }\end{array}$} & \multirow[b]{2}{*}{ Comments } \\
\hline Commanded & $\begin{array}{c}\text { Time } 1 \\
\text { Time } 2 \\
\text { Average time } \\
\end{array}$ & $\begin{array}{c}\mathrm{x} \text { distance } \\
\text { (in.) }\end{array}$ & $\begin{array}{c}y \text { distance } \\
\text { (in.) }\end{array}$ & & \\
\hline \multicolumn{6}{|l|}{$\begin{array}{l}100 \% \\
\text { Location A } \\
\end{array}$} \\
\hline \multicolumn{6}{|l|}{$\begin{array}{l}50 \% \\
\text { Location A }\end{array}$} \\
\hline \multicolumn{6}{|l|}{$\begin{array}{l}75 \% \\
\text { Location A }\end{array}$} \\
\hline \multicolumn{6}{|l|}{$\begin{array}{l}25 \% \\
\text { Location A }\end{array}$} \\
\hline & \multicolumn{3}{|c|}{ Signature } & \multicolumn{2}{|c|}{ Date } \\
\hline \multicolumn{6}{|l|}{ Recorded by: } \\
\hline \multicolumn{6}{|l|}{ Witnessed by: } \\
\hline Reviewed by: & & & & & \\
\hline
\end{tabular}



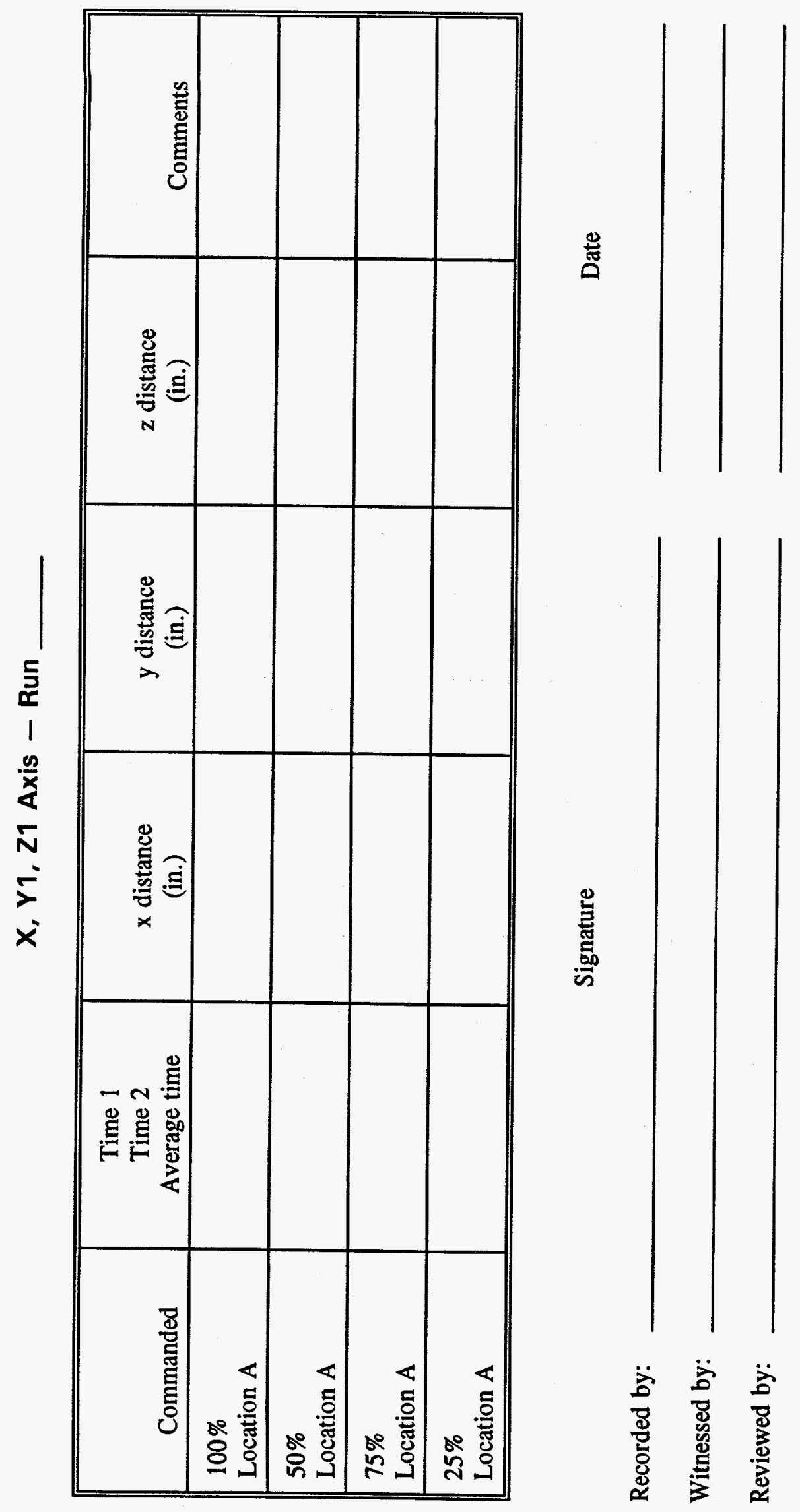


\section{INDEPENDENT MOVEMENT AND DEPLOYMENT OF TOOLS}

\section{A. General}

The independent test involves programming a 10 foot by 10 foot $\mathrm{x}-\mathrm{y}$ scan area for Z-mast $\mathrm{A}$. This will simulate scanning for Digface Characterization. At the same time, Z-mast B will be operated to monitor the scanning process of Z-mast A. (A camera will be held in the Z-mast B manipulator and used for visual monitoring.) $Z$-mast $B$ will be moved along its $y$-axis and $z$-axis during the scanning. The intent is to provide for enhanced video of the scanning exercise. The scanning exercise applies equally well to controlled vacuuming of a predefined area. Video will be taken to provide photographic evidence of the event.

The vacuum will be tested two separate ways; manually and using the zmast. Table A-3 shows the list of soil mixtures that will be tested. The capability of the vacuum for retrieving these targets will be recorded. The time it takes to retrieve each target (as shown in Table A-3) will be recorded for comparison to the subsequent tests. If the hose becomes clogged, causing a pressure drop, crushed gravel with sharp edges will be vacuumed to attempt to dislodge objects, remove sludge buildup, and clean the hose. The amount of gravel needed to regain pressure will be recorded to the nearest cup. Success will be determined based on at least $90 \%$ of the target being vacuumed. Manual and zmast deployment tests for the vacuum will be performed four times.

Table A-3. Targets for vacuum tests.

\begin{tabular}{||l||}
\hline \multicolumn{1}{|c|}{ Targets } \\
\hline 3 gal sand \\
\hline 3 gal gravel \\
\hline 3 gal $111 / 2$ inch rock \\
\hline
\end{tabular}

\section{B. Materials and Equipment}

The following materials and equipment will be required to perform the tests outlined above and described in detail below.

- One lab notebook

- Two pens

- Two stopwatches

- Gantry crane system and controls/displays

- Vacuum system

- Dig-face characterization system

- Soil mixtures as outlined in Table A-3 above 
- Equipment to mount the vacuum and dig-face characterization equipment to the crane

- Video camera for photographic evidence of tests

- Videotapes.

\section{Precautions}

No personnel should be in the immediate area of the gantry crane while it is in operation. The immediate area shall be defined by the PI and roped off accordingly. If the gantry crane needs to be repaired during the tests, power will be turned off.

\section{Procedure}

The following is a step-by-step procedure for completing the cooperative movement tests. The steps should be followed chronologically starting with step 1. Data will be recorded on the sheets given in A-2.5, "Data Collection Sheets," and taped into the logbook.

Step 1. Area readiness check.

Step 1.1 Ensure that the materials are within the working area. The materials will include the objects listed in Table A-3 and a video camera.

Step 1.2 Ensure that all obstructions and unnecessary materials are removed from the area.

Step 1.3 Ensure that the immediate area is roped off.

Step 2. Gantry readiness check.

Step 2.1 Unhook crane restraint.

Step 2.2 Verify manipulators are stowed.

Step 3. Start system.

Step 3.1 Power up the system.

Step 3.2 Start the hydraulics.

Step 3.3 Initialize the software.

Step 3.4 Home the crane.

Step 4. Start videotaping of the tests.

Step 5. Manually attach the simulated dig-face characterization equipment by placing it in the jaw of Arm \#1 of Z-mast A.

Step 6. Install the video camera in the jaws of Arm \#2 of Z-mast B. 
Step 7. Independent movement tests.

Step 7.1 Program a three point plane for Z-mast A. It shall be a 10 foot by 10 foot area. Rasters shall be 12 inches. Time the path planning and record the time in the data sheets. Follow movement of z-mast $A$ by jogging the $B$ Z-mast, $y, z$, axes with a camera held in the jaws of Schilling arm \#2 (mounted on Z-mast B).

Step 7.2 Execute the scan paths. Time and record in the data sheets. Manually follow " A" with "B" and record events on video.

Step 7.3 Repeat steps 7.1-7.2 three more times for different 10 foot by 10 foot areas.

Step 7.4 Secure system, following tests.

Step 8. Vacuum Test 1. The times and all deficiencies and difficulties should be recorded in the logbook. If at any time during this test, there is a pressure drop due to clogging the hose, vacuum crushed gravel and record (in the logbook) the amount of gravel (to the nearest cup) required to regain pressure. The vacuum holding bag should be emptied when required. The new trash should be disposed in regular trash. (Manual test)

Step 8.1 Vacuum the 1 gal of water. Record time.

Step 8.2 Vacuum the 1 gal of vegetable oil. Record time.

Step 8.3 Vacuum sponges. Record the time.

Step 8.4 Vacuum the six pieces of 8-1/2 $\times 11$-in. paper crinkled into balls. Record the time.

Step 8.5 Vacuum two flat pieces of 8-1/2 x 11-in. paper. Record the time.

Step 8.6 Vacuum two No. 2 pencils. Record the time.

Step 8.7 Vacuum two sets of rubber gloves. Record the time.

Step 8.8 Vacuum two yellow sticky pads. Record the time.

Step 8.9 Vacuum $3 \mathrm{lb}$ of nails. Record the time.

Step 8.10 Vacuum two crushed pop cans. Record the time.

Step 8.11 Vacuum 3 pieces of 2 yd of string. Record the time.

Step 8.12 Vacuum 20 standard paper clips. Record the time.

Step 8.13 Vacuum 3 gal of soil. Record the time. 
Step 8.14 Vacuum $3 \mathrm{gal}$ of sand. Record the time.

Step 8.15 Vacuum 3 gal of gravel. Record the time.

Step 8.16 Vacuum $3 \mathrm{gal}$ of $11 / 2$ inch rock. Record the time.

Step 8.17 Repeat Steps 8.1-8.16 three more times.

Step 9. Vacuum Test 2. The times and all deficiencies and difficulties should be recorded in the logbook. If at any time during this test, there is a pressure drop due to clogging the hose, vacuum crushed gravel and record (in the logbook) the amount of gravel (to the nearest cup) required to regain pressure. The vacuum holding bag should be emptied when required. The new trash should be disposed in regular trash. Deploy off of zmast Trolley A.

Step 9.1 Vacuum 3 gal of sand. Record the time.

Step 9.2 Vacuum 3 gal of gravel. Record the time.

Step 9.3 Vacuum 3 gal of 1 1/2 inch rock. Record the time.

Step 9.4 Repeat Steps 9.1-9.3 three more times.

Step 10. Additional vacuum tests.

Step 10.1 Vacuum from the sand pile using a three point plane (from zmast1).

Step 10.2 Replay the path with an offset of 3 inches lower.

Step 10.3 Repeat Steps 10.1-10.2 in the gravel pile.

Step 10.4 Repeat Steps 10.1-10.2 in the 1 1/2 inch rock pile.

Step 11. Stop videotaping.

Step 12. System shut down.

Step 12.1 Home the crane.

Step 12.2 Stow manipulators.

Step 12.3 Power down the crane and hydraulics.

\section{E. Data Collection Sheets}

Data shall be recorded on the following sheets and taped into the testing logbook. 


\section{Dig-Face Characterization Tests}

\begin{tabular}{|c|c|c|c|}
\hline Run & $\begin{array}{c}\text { Plan time } \\
\text { Time } 1 \\
\text { Time 2 } \\
\text { Average time } \\
\text { (seconds) }\end{array}$ & $\begin{array}{l}\text { Execute time } \\
\text { Time } 1 \\
\text { Time } 2 \\
\text { Average time } \\
\text { (seconds) } \\
\end{array}$ & Comments \\
\hline 1 & & & \\
\hline 2 & & & \\
\hline 3 & & & \\
\hline \multirow[t]{2}{*}{4} & & & \\
\hline & & & \\
\hline
\end{tabular}

Signature

Date

Recorded by:

Witnessed by:

Reviewed by: 
Vacuum Test Zmast - Run

\begin{tabular}{||l|l|l|l|l||}
\hline \multicolumn{1}{|c|}{ Target } & $\begin{array}{c}\text { Time 1 } \\
\text { Time 2 } \\
\text { Average time }\end{array}$ & \% of target vacuumed & $\begin{array}{c}\text { Success/failure } \\
\text { (S/F) }\end{array}$ & Comments \\
\hline 3 gal sand & & & & \\
\hline 3 gal gravel & & & & \\
\hline 3 gal $11 / 2$ inch rock & & & & \\
\hline
\end{tabular}

Signature

Date

Recorded by:

Witnessed by:

$\underset{\infty}{\infty}$ Reviewed by: 


\section{COOPERATIVE MOVEMENT}

\section{A. General}

Cooperative movement will be demonstrated using three operating scenarios. The first operation will involve rigging an oversized object and moving that object. This will entail cooperative movement of a manipulator and the hoist. The second operation will involve tracking the rigging operation with a camera held on the wrist of the second manipulator. This entails moving an object with one manipulator and tracking that movement using a camera held by the second manipulator. The third operation will involve handing an object from one manipulator to the other. Success will be measured based on accomplishing the tasks and will not be dependent on the time it takes to accomplish those tasks. A video of the operations will provide photographic evidence.

\section{B. Materials and Equipment}

The following materials and equipment will be required to perform the tests outlined above and described in detail below.

- One lab notebook

- Two pens

- Gantry crane system and controls/displays

- Oversized object, irregular shaped stainless steel vessel

- Rigging to move the oversized object

- Piece of wood to hand off from one manipulator to the other

- Video camera for tracking

- Video camera for photographic evidence of tests

- Videotapes.

\section{Precautions}

No personnel should be in the immediate area of the gantry crane while it is in operation. The immediate area shall be defined by the PI and roped off accordingly. If the gantry crane needs to be repaired during the tests, precautions for lock out and tag out shall be taken.

\section{Procedure}

The following is a step-by-step procedure for completing the cooperative movement tests. The steps should be followed chronologically starting with step 1 . Comments on performance of the system shall be recorded in the logbook.

Step 1. Area readiness check. 
Step 1.1 Ensure that the materials are within the working area. The materials will include the oversized object, the protected marker, a piece of wood, and a video camera.

Step 1.2 Ensure all obstructions and unnecessary materials are removed from the area.

Step 1.3 Ensure that the immediate area is roped off.

Step 2. Gantry readiness check.

Step 2.1 Unhook crane restraint.

Step 2.2 Verify manipulators are stowed.

Step 3. Start system.

Step 3.1 Power up the system.

Step 3.2 Start the hydraulics.

Step 3.3 Initialize the software.

Step 3.4 Home the crane.

Step 4. Start videotaping of the tests.

Step 5. Perform cooperative movement to rig and move an oversized object.

Step 5.1 Secure the manual barrel handler.

Step 5.2 Position crane and trolleys near vertically standing 55-gallon drum.

Step 5.3 The operator should teleoperate the manipulator to attach the barrel handler to the hoist.

Step 5.4 Using the second manipulator with the video camera attached, track the movements of the first manipulator to provide the operator the needed views to perform the attachment of the handler to the hoist. (Steps 5.3 and 5.4 should be performed simultaneously.)

Step 5.5 Using the y- and z-motions of the hoist, move the object to an offloading location.

Step 5.6 Remove the barrel handler and set in storage location.

Step 6. Perform cooperative movement to track an object using a camera.

Step 6.1 Pick up the piece of wood with one of the manipulators. 
Step 6.2 Attach a video camera to the other manipulator.

Step 6.3 Check to see that the video data are transmitting.

Step 6.4 Teleoperate the manipulator holding the piece of wood while attempting to follow the wood using the camera that is being held by the second manipulator. This step should allow movement of the wood to a wide range of area within the workspace and should be done for a minimum of 5 minutes.

Step 6.5 Set the video camera down on the staging area.

Step 7. Perform cooperative movement to hand an object from one manipulator to the other.

Step 7.1 Hand off a square piece of aluminum tubing from the manipulator hand to the other manipulator.

Step 7.2 Now hand the tubing back to the other manipulator.

Step 7.3 Set the tubing down on the staging area.

Step 8. Stop videotaping.

Step 9. System shut down.

Step 9.1 Home the crane.

Step 9.2 Stow manipulators.

Step 9.3 Power down the crane and hydraulics. 
Appendix B

Raw Data from the Delivery System Tests 


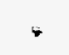


TARGET: 300 INCHES IN $\times$ DIRECTION. $1 / 19 / 95$

(REVA.PTS)

PT NAME PT\# $Y$-COORD. X-COORD. Z-COORD. TIME1 TIME2 \% OF $\begin{array}{llll}(\mathrm{ft}) & (\mathrm{ft}) \quad(\mathrm{ft}) \quad(\mathrm{m}: \mathrm{s}) & (\mathrm{m}: \mathrm{s}) & \text { FULL SPEED }\end{array}$

\begin{tabular}{llllllll}
\hline HOME & 7 & 16.904 & -72.926 & 1.510 & & & \\
XA11 & 8 & 16.903 & -47.943 & 1.520 & $0: 49$ & $\ldots$ & 100 \\
HOME & 12 & 16.853 & -72.902 & 1.505 & & & \\
XA12 & 13 & 16.856 & -47.980 & 1.510 & $1: 29$ & $1: 30$ & 50 \\
HOME & 16 & 16.847 & -72.909 & 1.505 & & & \\
XA13 & 17 & 16.857 & -47.980 & 1.510 & $1: 01$ & $\ldots$ & 75 \\
HOME & 20 & 16.852 & -72.908 & 1.505 & & & \\
XA14 & 21 & 16.863 & -47.988 & 1.510 & $2: 50$ & $2: 50$ & 25 \\
HOME & 24 & 16.867 & -72.909 & 1.505 & & & \\
XA21 & 25 & 16.860 & -47.979 & 1.510 & $0: 51$ & $0: 57$ & 100 \\
HOME & 26 & 16.865 & -72.905 & 1.500 & & & \\
XA22 & 27 & 16.865 & -47.951 & 1.510 & $1: 28$ & $1: 29$ & 50 \\
HOME & 28 & 16.864 & -72.879 & 1.505 & & & \\
XA23 & 29 & 16.864 & -47.951 & 1.510 & $1: 03$ & $1: 03$ & 75 \\
HOME & 30 & 16.866 & -72.879 & 1.505 & & & \\
XA24 & 31 & 16.871 & -47.959 & 1.510 & $2: 47$ & $2: 47$ & 25 \\
HOME & 32 & 16.866 & -72.884 & 1.505 & & & \\
XA31 & 33 & 16.869 & -47.949 & 1.510 & $0: 51$ & $0: 50$ & 100 \\
HOME & 34 & 16.874 & -72.877 & 1.505 & & & \\
XA32 & 35 & 16.850 & -47.950 & 1.510 & $1: 02$ & $1: 02$ & 75 \\
HOME & 36 & 16.846 & -72.873 & 1.505 & & & \\
XA33 & 37 & 16.851 & -47.929 & 1.510 & $1: 29$ & $1: 30$ & 50 \\
HOME & 38 & 16.847 & -72.858 & 1.500 & & & \\
XA34 & 39 & 16.850 & -47.929 & 1.510 & $2: 47$ & $2: 46$ & 25 \\
HOME & 40 & 16.848 & -72.852 & 1.500 & & & \\
XA41 & 41 & 16.852 & -47.929 & 1.510 & $0: 46$ & $0: 47$ & 100 \\
HOME & 42 & 16.850 & -72.857 & 1.510 & & & \\
XA42 & 43 & 16.848 & -47.925 & 1.505 & $1: 26$ & $1: 27$ & 50 \\
HOME & 44 & 16.847 & -72.847 & 1.505 & & & \\
XA43 & 45 & 16.854 & -47.928 & 1.510 & $1: 01$ & $1: 01$ & 75 \\
HOME & 46 & 16.845 & -72.874 & 1.500 & & & \\
XA44 & 47 & 16.851 & -47.961 & 1.510 & $2: 44$ & $2: 45$ & 25 \\
HOME & 48 & 16.848 & -72.878 & 1.505 & & & \\
XA51 & 49 & 16.852 & -47.929 & 1.510 & $0: 49$ & $0: 49$ & 100 \\
HOME & 50 & 16.836 & -72.860 & 1.505 & & & \\
XA52 & 51 & 16.855 & -47.927 & 1.510 & $1: 26$ & $1: 26$ & 50 \\
HOME & 52 & 16.851 & -72.846 & 1.500 & & & \\
XA53 & 53 & 16.855 & -47.928 & 1.510 & $1: 01$ & $1: 01$ & 75 \\
HOME & 54 & 16.855 & -72.876 & 1.505 & & & \\
XA54 & 55 & 16.851 & -47.961 & 1.510 & $2: 42$ & $2: 42$ & 25 \\
\hline & & & & & & & \\
\hline
\end{tabular}


TARGET: 300 INCHES IN Y DIRECTION.

1/20/95

(REVA2.PTS)

PT NAME PT\# Y-COORD. X-COORD Z-COORD TIME1 TIME2 \% OF $(\mathrm{ft}) \quad(\mathrm{ft}) \quad(\mathrm{ft}) \quad(\mathrm{m}: \mathrm{s})(\mathrm{m}: \mathrm{s})$ FULL SPEED

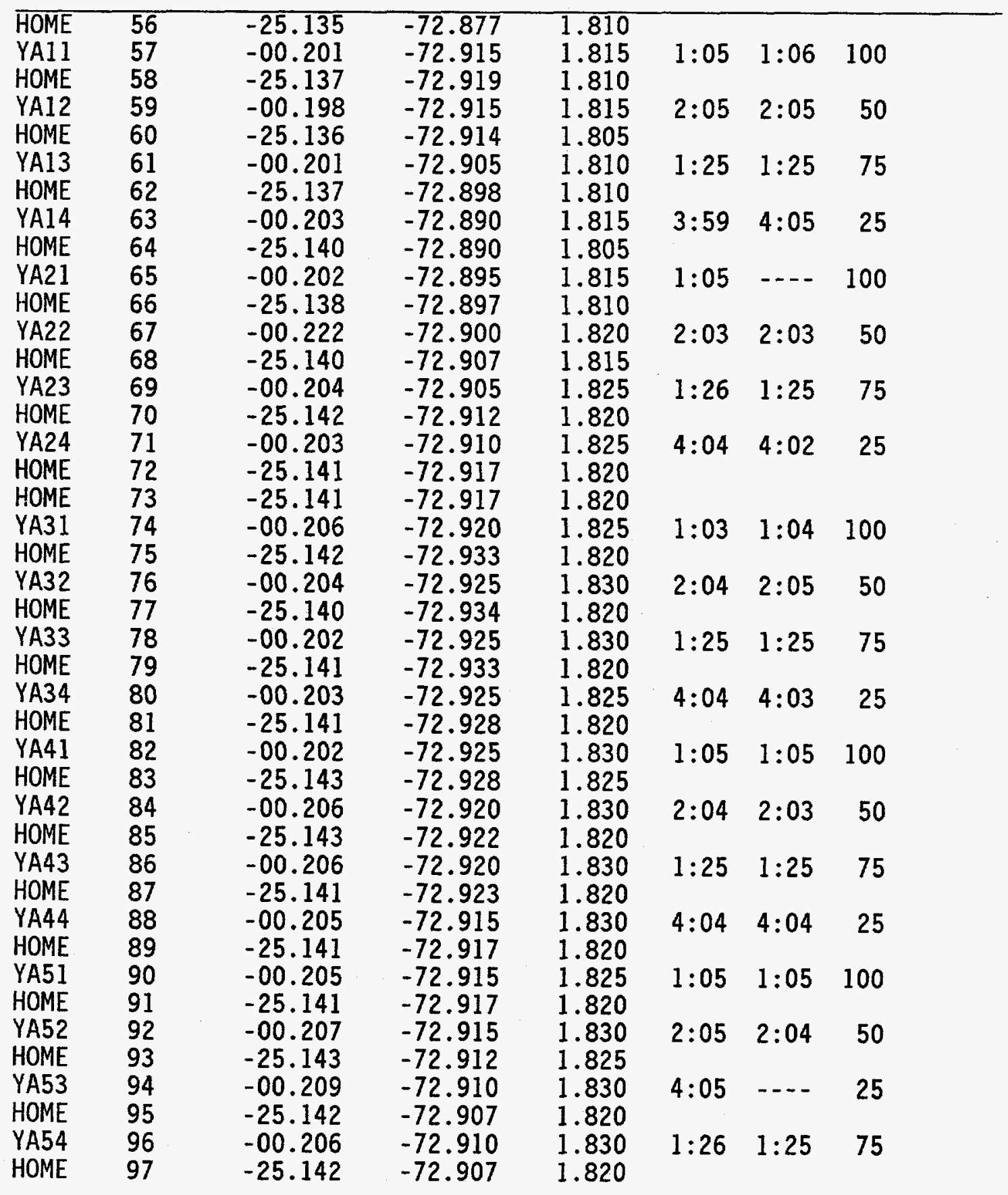


TARGET: 36 INCHES IN $Z$ DIRECTION. $1 / 20 / 95$

(REVA3.PTS)

PT NAME PT\# $Y$-COORD. X-COORD. Z-COORD. TIME1 TIME2 \% OF $(\mathrm{ft}) \quad(\mathrm{ft}) \quad(\mathrm{ft}) \quad(\mathrm{m}: \mathrm{s})(\mathrm{m}: \mathrm{s})$ FULL SPEED

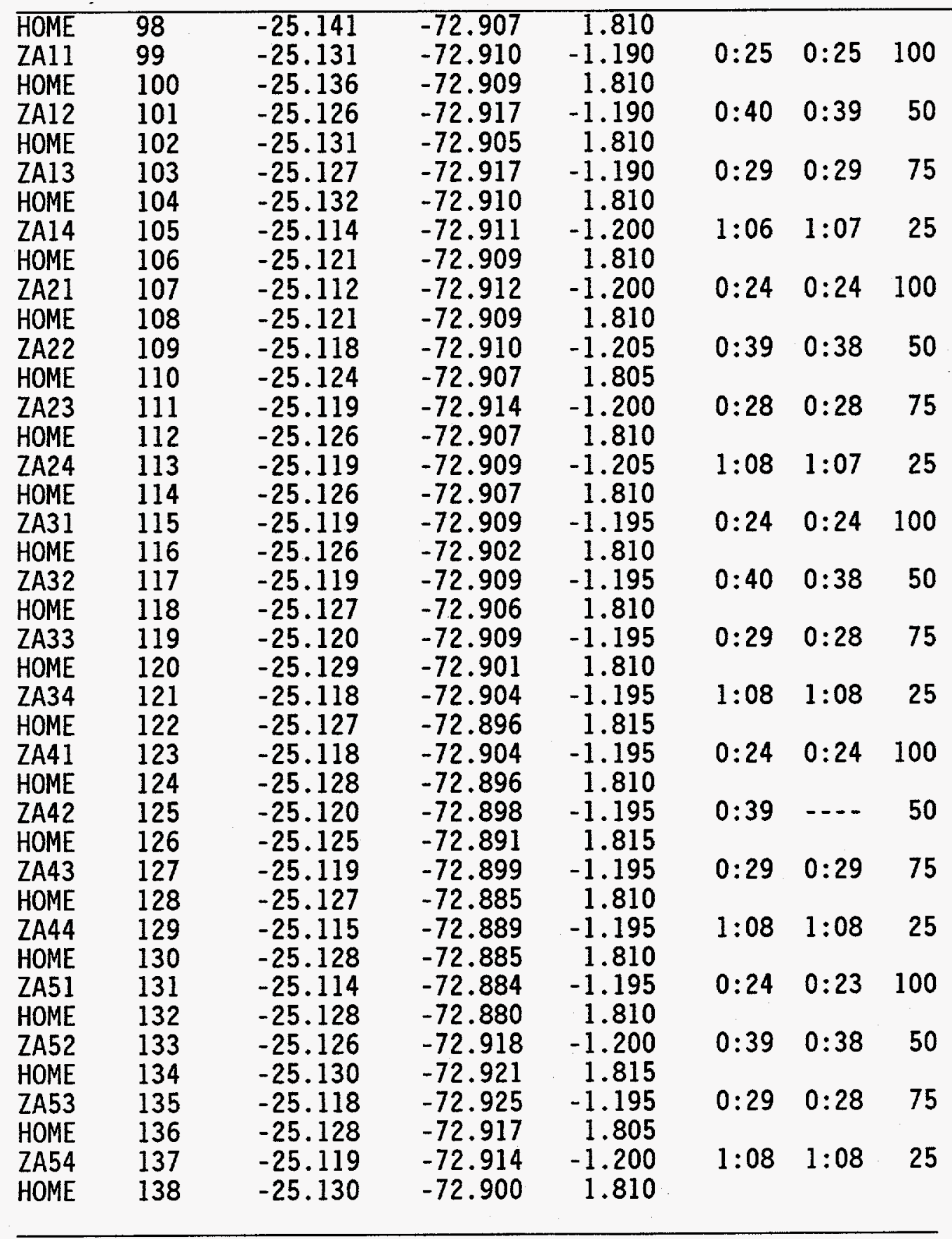


TARGET: 100 INCHES IN Y DIRECTION, 100 INCHES IN $X$ DIRECTION, AND 36 INCHES IN Z DIRECTION.

$1 / 20 / 95$

(REVA4.PTS)

PT NAME PT\# Y-COORD. X-COORD. Z-COORD. TIME1 TIME2 \% OF

$(\mathrm{ft}) \quad(\mathrm{ft}) \quad(\mathrm{ft}) \quad(\mathrm{m}: \mathrm{s}) \quad(\mathrm{m}: \mathrm{s})$ FULL SPEED

\begin{tabular}{llrrrrrr}
\hline XYZ11 & 139 & -16.803 & -64.585 & -1.195 & $0: 28$ & --- & 100 \\
HOME & 140 & -25.153 & -72.929 & 1.805 & & & \\
XYZ12 & 141 & -16.806 & -64.600 & -1.190 & $0: 46$ & $0: 47$ & 50 \\
HOME & 142 & -25.150 & -72.925 & 1.810 & & & \\
XYZ13 & 143 & -16.807 & -64.599 & -1.195 & $0: 35$ & $0: 35$ & 75 \\
HOME & 144 & -25.149 & -72.925 & 1.810 & & & \\
XYZ14 & 145 & -16.804 & -64.611 & -1.190 & $1: 26$ & $1: 26$ & 25 \\
HOME & 146 & -25.149 & -72.931 & 1.810 & & & \\
XYZ21 & 147 & -16.802 & -64.596 & -1.190 & $0: 28$ & $0: 27$ & 100 \\
HOME & 148 & -25.146 & -72.926 & 1.810 & & & \\
XYZ22 & 149 & -16.803 & -64.601 & -1.190 & $0: 45$ & $0: 46$ & 50 \\
HOME & 150 & -25.151 & -72.930 & 1.805 & & & \\
XYZ23 & 151 & -16.802 & -64.601 & -1.195 & $0: 34$ & $0: 34$ & 75 \\
HOME & 152 & -25.149 & -72.931 & 1.805 & & & \\
XYZ24 & 153 & -16.793 & -64.582 & -1.185 & $1: 26$ & $1: 26$ & 25 \\
HOME & 154 & -25.149 & -72.931 & 1.805 & & & \\
XYZ31 & 155 & -16.803 & -64.606 & -1.195 & $0: 27$ & $0: 28$ & 100 \\
HOME & 156 & -25.149 & -72.931 & 1.810 & & & \\
XYZ32 & 157 & -16.802 & -64.601 & -1.195 & $0: 47$ & $0: 47$ & 50 \\
HOME & 158 & -25.153 & -72.950 & 1.810 & & & \\
XYZ33 & 159 & -16.801 & -64.601 & -1.195 & $0: 33$ & $0: 34$ & 75 \\
HOME & 160 & -25.150 & -72.930 & 1.805 & & & \\
XYZ34 & 161 & -16.797 & -64.602 & -1.185 & $1: 27$ & $1: 26$ & 25 \\
HOME & 162 & -25.152 & -72.951 & 1.805 & & & \\
XYZ41 & 163 & -16.791 & -64.567 & -1.190 & $0: 27$ & $0: 28$ & 100 \\
& & & & & & &
\end{tabular}


Appendix C

Raw Data from the Vacuum Tests 


\section{Appendix C}

\section{Raw Data From the Vacuum Tests}

Manual Test - Run 1

\begin{tabular}{|l|l|l|l|l|}
\hline \multicolumn{1}{|c|}{ Target } & \multicolumn{1}{|c|}{$\begin{array}{c}\text { Time 1 } \\
\text { Time 2 }\end{array}$} & $\begin{array}{c}\text { \% of Target } \\
\text { Retrieved }\end{array}$ & $\begin{array}{l}\text { Success or } \\
\text { Failure }\end{array}$ & \multicolumn{1}{c|}{ Comments } \\
\hline 3 gal sand & $\begin{array}{l}14.80 \mathrm{~s} \\
14.85 \mathrm{~s}\end{array}$ & $99 \%$ & Success & $\begin{array}{l}21 / 2^{\prime \prime} \text { mercury } \\
\text { max }\end{array}$ \\
\hline 3 gal soil & $21.40 \mathrm{~s}$ & $99 \%$ & Success & $2^{\prime \prime}$ mercury max \\
\hline 3 gal gravel & $\begin{array}{l}17.07 \mathrm{~s} \\
17.12 \mathrm{~s}\end{array}$ & $99 \%$ & Success & $\begin{array}{l}21 / 2^{\prime \prime} \text { mercury } \\
\text { max }\end{array}$ \\
\hline $\begin{array}{l}3 \text { gal 1-1/2" } \\
\text { rock }\end{array}$ & $24.89 \mathrm{~s}$ & $99 \%$ & Success & $\begin{array}{l}1^{\prime \prime} \text { mercury max, } \\
\text { 3 rocks not } \\
\text { vacuumed }\end{array}$ \\
\hline
\end{tabular}

Manual Test - Run 2

\begin{tabular}{|l|l|l|l|l|}
\hline \multicolumn{1}{|c|}{ Target } & \multicolumn{1}{|c|}{$\begin{array}{c}\text { Time 1 } \\
\text { Time 2 }\end{array}$} & $\begin{array}{c}\text { \% of Target } \\
\text { Retrieved }\end{array}$ & $\begin{array}{l}\text { Success or } \\
\text { Failure }\end{array}$ & Comments \\
\hline 3 gal sand & $\begin{array}{l}18.91 \mathrm{~s} \\
18.04 \mathrm{~s}\end{array}$ & $99 \%$ & Success & None \\
\hline 3 gal soil & $22.13 \mathrm{~s}$ & $99 \%$ & Success & Chunk of soil \\
\hline 3 gal gravel & $\begin{array}{l}11.78 \mathrm{~s} \\
11.81 \mathrm{~s}\end{array}$ & $99 \%$ & Success & None \\
\hline $\begin{array}{l}3 \text { gal } 1-1 / 2^{\prime \prime} \\
\text { rock }\end{array}$ & $\begin{array}{l}19.28 \mathrm{~s} \\
19.72 \mathrm{~s}\end{array}$ & $99 \%$ & Success & $\begin{array}{l}11 \text { rocks not } \\
\text { vacuumed }\end{array}$ \\
\hline
\end{tabular}


Manual Test - Run 3

\begin{tabular}{|l|l|l|l|l|}
\hline \multicolumn{1}{|c|}{ Target } & \multicolumn{1}{|c|}{$\begin{array}{c}\text { Time 1 } \\
\text { Time 2 }\end{array}$} & $\begin{array}{c}\text { \% of Target } \\
\text { Retrieved }\end{array}$ & $\begin{array}{l}\text { Success or } \\
\text { Failure }\end{array}$ & \multicolumn{1}{c|}{ Comments } \\
\hline 3 gal sand & $\begin{array}{l}13.88 \mathrm{~s} \\
13.55 \mathrm{~s}\end{array}$ & $99 \%$ & Success & None \\
\hline 3 gal soil & $17.91 \mathrm{~s}$ & $99 \%$ & Success & plunging worked \\
\hline 3 gal gravel & $\begin{array}{l}13.12 \mathrm{~s} \\
13.17 \mathrm{~s}\end{array}$ & $99 \%$ & Success & None \\
\hline $\begin{array}{l}\text { 3 gal } 1-1 / 2^{\prime \prime} \\
\text { rock }\end{array}$ & $\begin{array}{l}22.86 \mathrm{~s} \\
\text { No time }\end{array}$ & $99 \%$ & Success & $\begin{array}{l}\text { 20 rocks not } \\
\text { vacuumed }\end{array}$ \\
\hline
\end{tabular}

Manual Test - Run 4

\begin{tabular}{|l|l|l|l|l|}
\hline \multicolumn{1}{|c|}{ Target } & \multicolumn{1}{|c|}{$\begin{array}{c}\text { Time 1 } \\
\text { Time 2 }\end{array}$} & $\begin{array}{c}\text { \% of Target } \\
\text { Retrieved }\end{array}$ & $\begin{array}{l}\text { Success or } \\
\text { Failure }\end{array}$ & \multicolumn{1}{c|}{ Comments } \\
\hline 3 gal sand & $\begin{array}{l}16.59 \mathrm{~s} \\
15.45 \mathrm{~s}\end{array}$ & $99 \%$ & Success & None \\
\hline 3 gal soil & $15.87 \mathrm{~s}$ & $99 \%$ & Success & None \\
\hline 3 gal gravel & $\begin{array}{l}12.68 \mathrm{~s} \\
12.68 \mathrm{~s}\end{array}$ & $99 \%$ & Success & None \\
\hline $\begin{array}{l}3 \text { gal } 1-1 / 2^{\prime \prime} \\
\text { rock }\end{array}$ & $\begin{array}{l}23.81 \mathrm{~s} \\
23.82 \mathrm{~s}\end{array}$ & $99 \%$ & Success & $\begin{array}{l}7 \text { rocks not } \\
\text { vacuumed }\end{array}$ \\
\hline
\end{tabular}




\section{Raw Data From the Vacuum Tests}

Zmast Test - Run 1

\begin{tabular}{|c|c|c|c|c|}
\hline Target & $\begin{array}{r}\text { Time 1 } \\
\text { Time } 2 \\
\text { (min:s) }\end{array}$ & $\begin{array}{c}\text { \% of Target } \\
\text { Retrieved }\end{array}$ & $\begin{array}{l}\text { Success or } \\
\text { Failure }\end{array}$ & Comments \\
\hline 3 gal sand & $\begin{array}{l}2: 06 \\
2: 06\end{array}$ & $92 \%$ & Success & Frozen clods left \\
\hline 3 gal gravel & $\begin{array}{l}3: 20 \\
3: 29\end{array}$ & $98 \%$ & Success & $\begin{array}{l}\text { Changed heights } \\
\text { twice }\end{array}$ \\
\hline $\begin{array}{l}3 \text { gal } 1-1 / 2^{\prime \prime} \\
\text { rock }\end{array}$ & $\begin{array}{l}2: 35 \\
2: 35\end{array}$ & $99 \%$ & Success & No comments \\
\hline
\end{tabular}

Zmast - Run 2

\begin{tabular}{|l|l|l|l|l|}
\hline \multicolumn{1}{|c|}{ Target } & \multicolumn{1}{|c|}{$\begin{array}{c}\text { Time 1 } \\
\text { Time 2 }\end{array}$} & $\begin{array}{c}\text { \% of Target } \\
\text { Retrieved }\end{array}$ & $\begin{array}{l}\text { Success or } \\
\text { Failure }\end{array}$ & Comments \\
\hline 3 gal sand & $\begin{array}{l}1: 45 \\
\text { No time }\end{array}$ & $91 \%$ & Success & No comments \\
\hline 3 gal gravel & $\begin{array}{l}1: 45 \\
1: 45\end{array}$ & $96 \%$ & Success & $\begin{array}{l}\text { Nonuniform } \\
\text { raster }\end{array}$ \\
\hline $\begin{array}{l}3 \text { gal } 1-1 / 2^{\mathrm{N}} \\
\text { rock }\end{array}$ & $\begin{array}{l}2: 54 \\
2: 56\end{array}$ & $92 \%$ & Success & $\begin{array}{l}\text { Nozzle shoves } \\
\text { some to side } \\
\text { where we } \\
\text { already } \\
\text { vacuumed }\end{array}$ \\
\hline
\end{tabular}


Zmast Test - Run 3

\begin{tabular}{|l|l|l|l|l|}
\hline Target & \multicolumn{1}{|c|}{$\begin{array}{c}\text { Time 1 } \\
\text { Time 2 } \\
\text { (min:s) }\end{array}$} & $\begin{array}{c}\text { \% of Target } \\
\text { Retrieved }\end{array}$ & $\begin{array}{l}\text { Success or } \\
\text { Failure }\end{array}$ & Comments \\
\hline 3 gal sand & $\begin{array}{l}2: 35 \\
2: 35\end{array}$ & $98 \%$ & Success & $\begin{array}{l}\text { Straight raster- } \\
\text { due to variability } \\
\text { in } \mathrm{x} \text { and not } y\end{array}$ \\
\hline 3 gal gravel & $\begin{array}{l}2: 09 \\
2: 09\end{array}$ & $99 \%$ & Success & No comments \\
\hline $\begin{array}{l}\text { 3 gal 1-1/2" } \\
\text { rock }\end{array}$ & $\begin{array}{l}2: 58 \\
2: 58\end{array}$ & $90 \%$ & Success & No comments \\
\hline
\end{tabular}

Zmast Test - Run 4

\begin{tabular}{|l|l|l|l|l|}
\hline \multicolumn{1}{|c|}{ Target } & \multicolumn{1}{|c|}{$\begin{array}{c}\text { Time 1 } \\
\text { Time 2 }\end{array}$} & $\begin{array}{c}\text { \% of Target } \\
\text { Retrieved }\end{array}$ & $\begin{array}{c}\text { Success or } \\
\text { Failure }\end{array}$ & Comments \\
\hline 3 gal sand & $2: 16$ & $90 \%$ & Success & No comments \\
& $2: 17$ & & & \\
\hline 3 gal gravel & $2: 37$ & $93 \%$ & Success & No comments \\
& $2: 36$ & & Success & No comments \\
\hline $\begin{array}{l}\text { 3 gal } 1-1 / 2^{\prime \prime} \\
\text { rock }\end{array}$ & $2: 06$ & $94 \%$ & & \\
\hline
\end{tabular}

